Article

\title{
Comparison of Energy Dissipation, Stiffness, and Damage of Structural Oriented Strand Board (OSB), Conventional Gypsum, and Viscoelastic Gypsum Shearwalls Subjected to Cyclic Loads
}

\section{David W. Dinehart ${ }^{1, *}$ and Andrew S. Blasetti ${ }^{2}$}

1 Department of Civil and Environmental Engineering, Villanova University, 800 Lancaster Avenue, Villanova, PA 19085, USA

2 Thornton Tomasetti, 744 Broad Street, Newark, NJ 07102, USA;

E-Mail: ablasetti@ThorntonTomasetti.com

* Author to whom correspondence should be addressed; E-Mail: david.dinehart@villanova.edu; Tel.: +1-610-519-4962; Fax: +1-610-519-6754.

Received: 3 May 2012 / Accepted: 11 June 2012 / Published: 28 June 2012

\begin{abstract}
A key element in the seismic load resisting system of a wood framed structure is the shear wall which is typically sheathed on one side with plywood or oriented strand board (OSB) and gypsum on the other. The shear capacity of gypsum sheathed shear walls is typically neglected in high seismic areas due to the susceptibility of conventional drywall screw connections to damage caused by earthquakes. The earthquake resistance of an innovative viscoelastic (VE) gypsum shearwall is evaluated and compared to conventional structural and non-structural walls. Ten $8 \mathrm{ft} \times 8 \mathrm{ft}$ wood framed wall specimens of three configurations [nailed-OSB, screw-gypsum, and VE polymer-gypsum] were subjected to a cyclic test protocol. The energy dissipation, stiffness, and damage characteristics of all shearwalls are reported herein. Testing results indicate the VE-gypsum walls can dissipate more energy than the OSB structural panels and 500\% more energy that the conventional gypsum sheathed walls and contains a constant source of energy dissipation not seen in the structural and non-structural walls. The wall stiffness of the OSB wall degrades at a far greater rate that the VE gypsum wall and at continued cycling degrades below the VE wall stiffness. Unlike both of the conventional wall types, the VE wall showed no visible or audible signs of damage when subjected to shear displacements up to 1.
\end{abstract}

Keywords: wood shearwall; seismic; gypsum; viscoelastic polymer; energy dissipation 


\section{Introduction}

Light-frame wood structures are quite common throughout North America due to their high strength-to-weight ratio. Their ductility via inelastic deformation protects human life during moderate to large earthquakes, but leads to economic hardship afterwards. Nonstructural, structural, and secondary damage add considerable financial burden to home owners and insurance companies. In the United States, the devastating 6.7 magnitude Northridge earthquake damaged tens of thousands of residential homes. Over $\$ 20$ billion in property damage and the loss of nearly 48,000 housing units was due to the inadequacy of wood-frame construction [1]. With today's need for performance-based design, the demand for new and innovative ideas for energy dissipation in wood-frame structures has grown considerably.

The major lateral load-resisting system for a light-frame wood structure consists of floor diaphragms, roof diaphragms, and vertical shear walls. Wood-frame shear walls have a critical role in preventing the destruction of residential buildings in earthquake regions - they transfer horizontal inertia forces from one floor to the next and ultimately to the foundation. Earthquakes inflict significant damage to wood shear walls. Sheathing-to-frame connections have been identified as the primary source of degrading performance and are now reinforced via reduced nail spacing, stronger nails, and thicker panels [2]. This guideline, however, is not as effective as one might expect due to the degradation of nailed sheathing connections subjected to dynamic loading [3]. As sheathing connections are lost, the wall damage continues and a reduction in stiffness and energy dissipation continues with each passing cycle of displacement.

Generally, nonstructural elements such as gypsum wall board and exterior finishes are not counted on in design of the lateral force resisting system. Attempts to quantify the value of nonstructural elements aiding in reducing seismic response have been made [4]. Shake table testing was conducted of a two-story, single family woodframe house with and without interior gypsum wall board and exterior wall finish materials. The structure with the wall finishes showed an increase in lateral stiffness and a substantial reduction in its seismic displacement response. The tests however, were unable to isolate the individual contribution of the gypsum wallboard and the exterior finish. Damage in the structure included diagonal cracking in the gypsum wallboard and stucco.

The damage threshold of nonstructural gypsum wallboard partition walls subjected to seismic loads was investigated with a series of 11 full-scale woodframe partitions sheathed on both sides with $13 \mathrm{~mm}$ gypsum [5]. Typical wall damage evident in all wall tests included fasteners pulling through the gypsum, cutting the gypsum, or tearing through the edge of the panel. Since the gypsum is not counted on for its structural use, this damage is considered nonstructural. Never the less, this damage caused during an earthquake can be extensive and expensive.

While gypsum wallboard is typically disregarded as a structural material, many experiments have shown that it does add to the structural capacity of the wall system. The shear capacity of shear walls sheathed with gypsum wallboard was investigated in thirty woodframe walls tests [6]. It was shown that wallboard orientation greatly affected strength and stiffness of the shear walls. Walls tested with panels oriented horizontally were over $40 \%$ stronger and stiffer than those with vertical panels. The results of this study allow structural engineers to consider the effects of gypsum wallboard when designing a structure to resist wind and seismic loads. In another study, the performance of shear walls 
sheathed with gypsum wallboard was compared to shear walls sheathed with plywood [7]. It was concluded that the contribution of gypsum sheathing to racking strength was significant compared to plywood, with gypsum wallboard on one side provided $38 \%-64 \%$ the racking strength produced by shear walls with plywood on one side, and 30\%-39\% the racking strength of shear walls sheathed with plywood opposite gypsum wallboard.

Shear walls with finish materials including gypsum were investigated in an effort to characterize their damage patterns [8]. Tested shear walls contained window and or door openings. At $0.2 \%$ drift, the gypsum wallboard sustained damage confined to small hairline cracks near the wall openings. Cracks were typically less than 0.002 " wide. A small number of sheathing connections exhibited a bulging effect in the sheathing material near the edges of the panels. At $0.4 \%$ drift, the gypsum wallboard panels began to deteriorate and crack at the corners of the openings. Cracks ranged from 0.005 " to 0.025 " wide. Tearing along the taped joints also became evident. At $0.7 \%$ drift, the cracks ranged from less than 0.002 " to 0.05 " wide. Tearing along the taped joints and bulging near the sheathing connections were more pronounced.

As part of the NEESWood project there was a focus on a performance-based seismic design (PBSD) philosophy for woodframed structures. Experimental studies as part of this project included large scale shake table testing of a full-scale, two story, light frame wood townhouse building, designed according to modern U.S. engineered seismic design requirements [9] and a full-scale mid-rise, six story, light frame wood apartment building [10,11]. Additionally a seismic performance assessment of woodframed structures with energy dissipation systems was conducted $[12,13]$.

The two story building structure was tested on two tri-axial shake tables operating simultaneously. The scope of this portion of project was to determine the dynamic characteristics and the seismic response of the structure under various base input intensities that were representative of ordinary and near-field ground motions typical in California. The structure was tested with and without gypsum wallboard finished on the interior and stucco finishes on the exterior. The experimental results clearly showed that the addition of gypsum wall board to the interior structural wood sheathed walls substantially improved the seismic response of the test structure. Additionally, the addition of stucco to the exterior added to the improved seismic response. The improvement was most noticeable in the longitudinal direction, where the shear response of low aspect ratio wall piers dominated the response. This work was a major step forward in noting the significance of gypsum and stucco in improving the seismic performance of the lateral-load resisting systems in light-frame wood construction [9].

The goals of the experimental testing program of the six story apartment building were to demonstrate that the performance-based design procedure developed as part of NEESWood worked on a full-scale building and to gain a better understanding of how mid-rise light-frame wood buildings respond to a major earthquake (2500 year event for Los Angeles, California). Additionally, the testing was intended to provide a baseline data set to the earthquake engineering community. An enormous amount of data was collected from numerous tests, including base shears, wall drifts, inter-story drifts, accelerations, hold-down forces and roof drifts that highlighted many significant findings; however, the information most relevant to the research reported herein focuses on the damage assessment of the test structure [10].

Another goal of the six-story shake table testing in the NEESWood project was focused on how the various construction elements influenced the seismic behavior of woodframed structures so that they 
could be better considered in the PBSD philosophy. To examine this issue several 50 year seismic tests were conducted at various stages of construction. The drywall panels were "normal" strength Japanese drywall panels. The panels were installed with tape and putty on all joints except the wall-to-ceiling joints and corners. The gypsum wall board was repaired between tests; however, the sill plates were not. Visual damage inspections were conducted after all tests. No edge tearout of the gypsum was evidenced due to the fact that large edge distances had been prescribed in this engineered building. Overall damage was characterized as non-structural damage. Most cracking was located at door and window openings and propagated diagonally outward, similar to damage that is typical for a moderate earthquake. Overall, the building performed very well during all earthquakes reviewed. There was no damage to any wood components in the building. The only damage found was attributed to the gypsum wallboard and noted to be non-structural [11].

While this recent information in regards to full-scale performance will aid design engineers, there is currently a lack of information regarding the dynamic effects of interior and exterior wall finishes on a structure. The extensive damage caused by earthquakes has led to the disposition of gypsum wallboard as a non-structural material. The initial response is to reduce the amount of allowable stress for gypsum-sheathed shear walls. In fact, these walls are typically neglected when designing a structure's lateral load-resisting system-especially in high seismic regions. However, simply neglecting the effects of a structural element can result in an overly conservative and possibly dangerous design. Generally, load acting upon a system is attracted to members with higher stiffness, so by neglecting an element's stiffness one might develop a misunderstanding of the overall structural system behavior. The attraction of force on certain walls during an earthquake may be considerably larger than anticipated, resulting in additional damage and potential collapse.

The objective of this research is to improve the seismic performance of wood-frame shear walls (i.e., increase energy dissipation while reducing damage to the wall) by utilizing gypsum sheathing attached by a viscoelastic (VE) polymer. A wall that undergoes neither structural nor non-structural damage during earthquakes has the potential to save lives and billions of dollars worth in repairs for homeowners and insurance companies. The isolated performance of the VE polymer is relevant, but beyond the scope of this paper. Details related to the hysteretic behavior, stiffness and energy dissipation characteristics of the VE polymer have been well documented [14-18]. Described herein are the results of an experimental study investigating the dynamic behavior (hysteresis form, energy dissipation, stiffness, and damage pattern) of three shearwall types: 1. conventional structural walls (nailed - oriented strand board, OSB), conventional non-structural walls (screws/gypsum), and VE walls (VE polymer/gypsum).

\section{Shearwall Specimens}

Three types of wood-frame shear walls are presented in this study: walls sheathed with oriented strand board using conventional nailed sheathing connections (OSBwall), walls sheathed with gypsum wallboard using conventional screwed connections (GYPwall), and walls sheathed with gypsum wallboard using viscoelastic connections (VEwall). Most wood-frame shear walls are designed with either OSB or plywood sheathing; therefore, the OSBwall specimens are considered the structural walls. The GYPwalls are conventional gypsum sheathed walls that are generally considered non-structural, 
while the VEwall specimens represent a modified shear wall design. The framing of all walls consisted of Spruce-Pine-Fir (SPF) 2 in. $\times 4$ in. lumber. Four OSBwall specimens, shown in Figure 1, were constructed. The walls were sheathed with 7/16" OSB which was connected to the framing via Bostich 8d clipped-head cooler nails driven by a pneumatic Bostich nail gun. Nails were spaced 4" around the perimeter of each panel with an edge spacing of 3/4" along the end studs and sill plates and 3/8" along the center stud. Nails along the field studs were spaced every 12 ".

Figure 1. OSBwall (oriented strand board) Specimen.

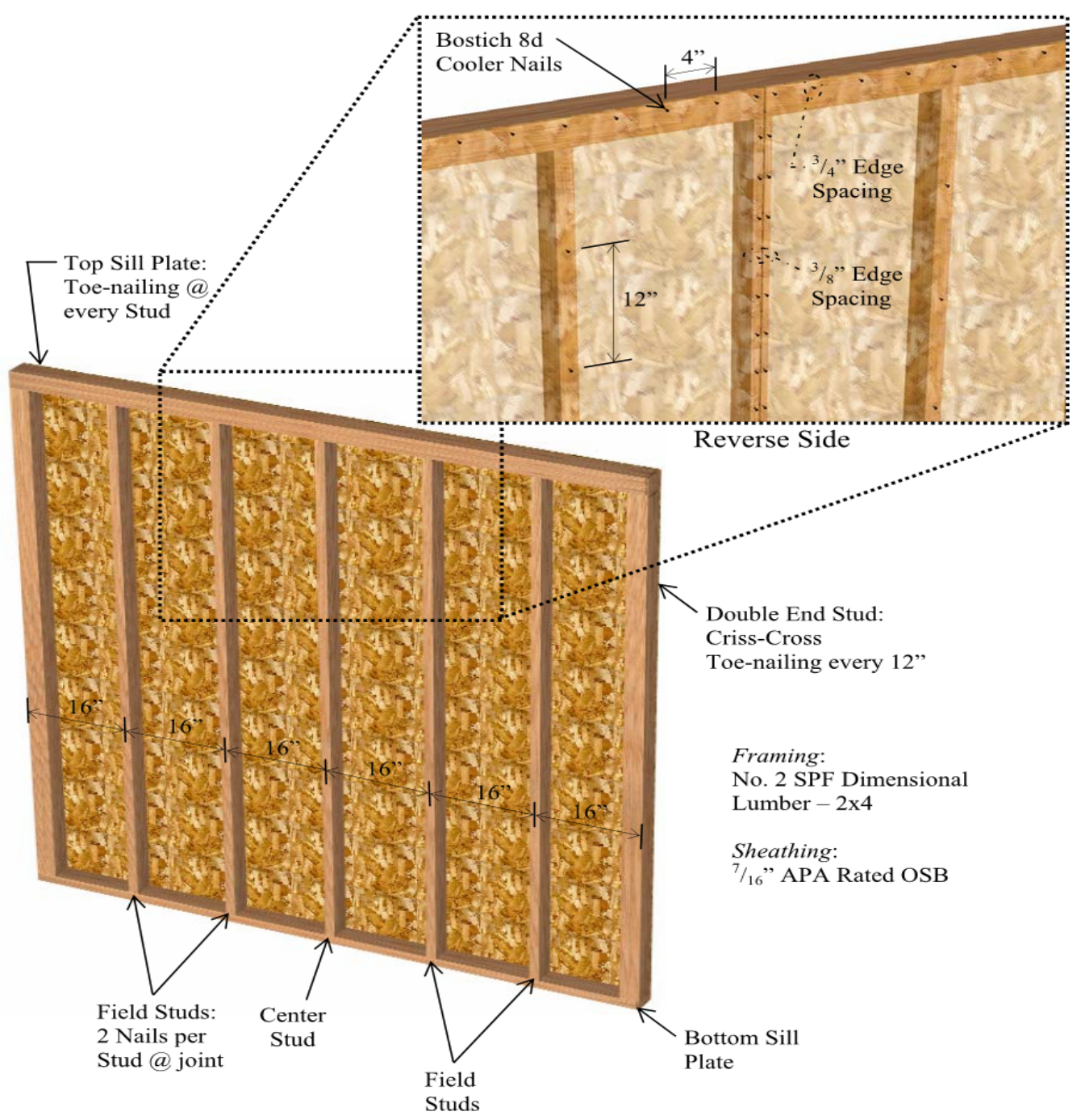

Three $8 \mathrm{ft} \times 8 \mathrm{ft}$ gypsum shear walls (GYPwall) and three VE gypsum shear walls (VEwall) were constructed and tested. The GYPwall and VEwall specimens, shown in Figure 2, consisted of two $4 \mathrm{ft} \times 8 \mathrm{ft}$ gypsum panels $1 / 2 \mathrm{in}$. thick oriented vertically and separated by $0.125 \mathrm{in}$. The end studs and top sill plate are comprised of two studs nailed together, while all other studs as well as the bottom sill plate were made from one stud. Framing members were connected together with two $16 \mathrm{~d} 3+1 / 2$ in. nails at every joint and $1+1 / 4$ in. drywall screws spaced at 12 in. along the perimeter and the field connected the gypsum to the frame. 
Figure 2. (a) GYPwall (gypsum) specimen; and (b) VEwall (viscoelastic) specimen.

(a)

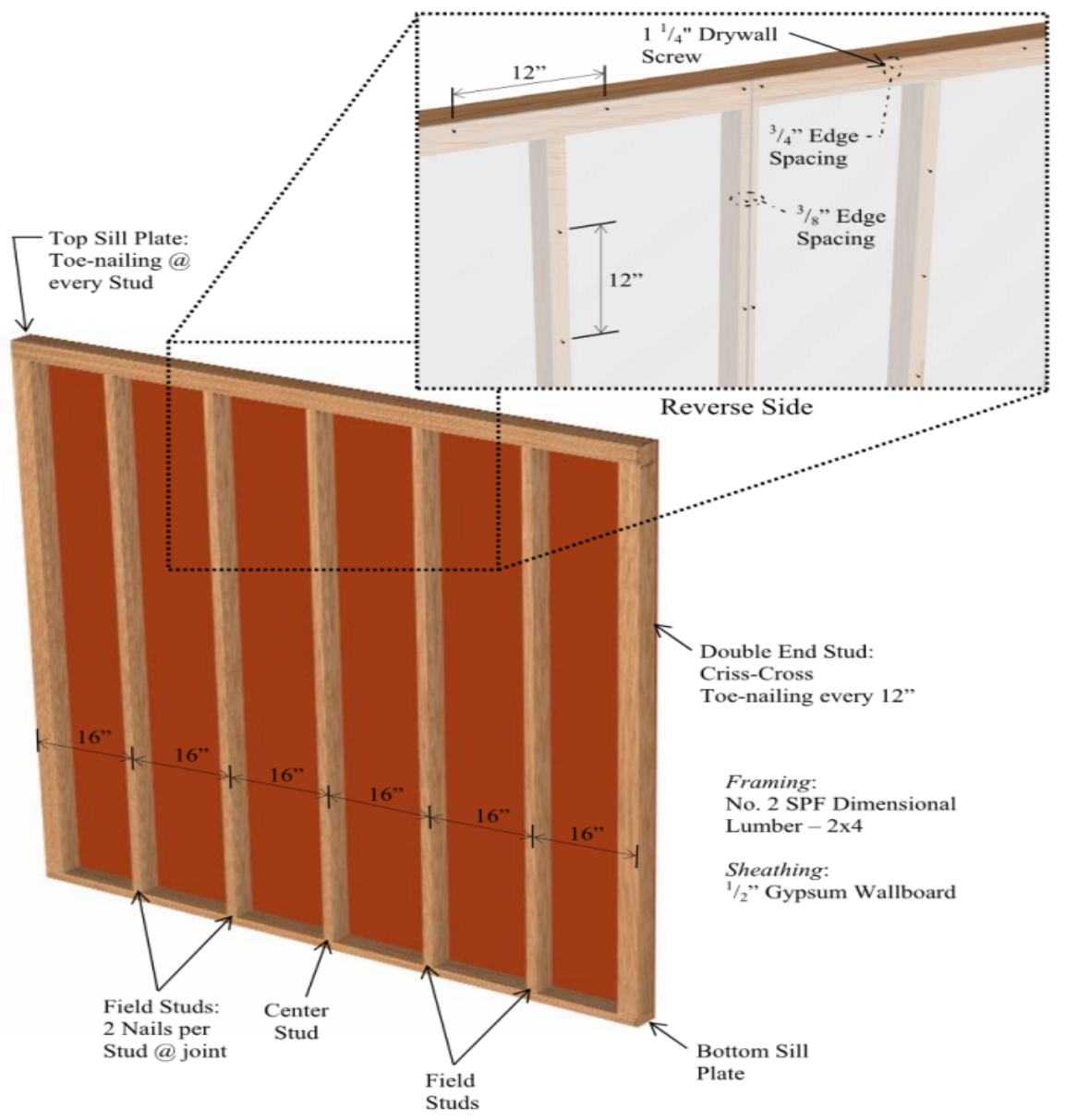

(b)

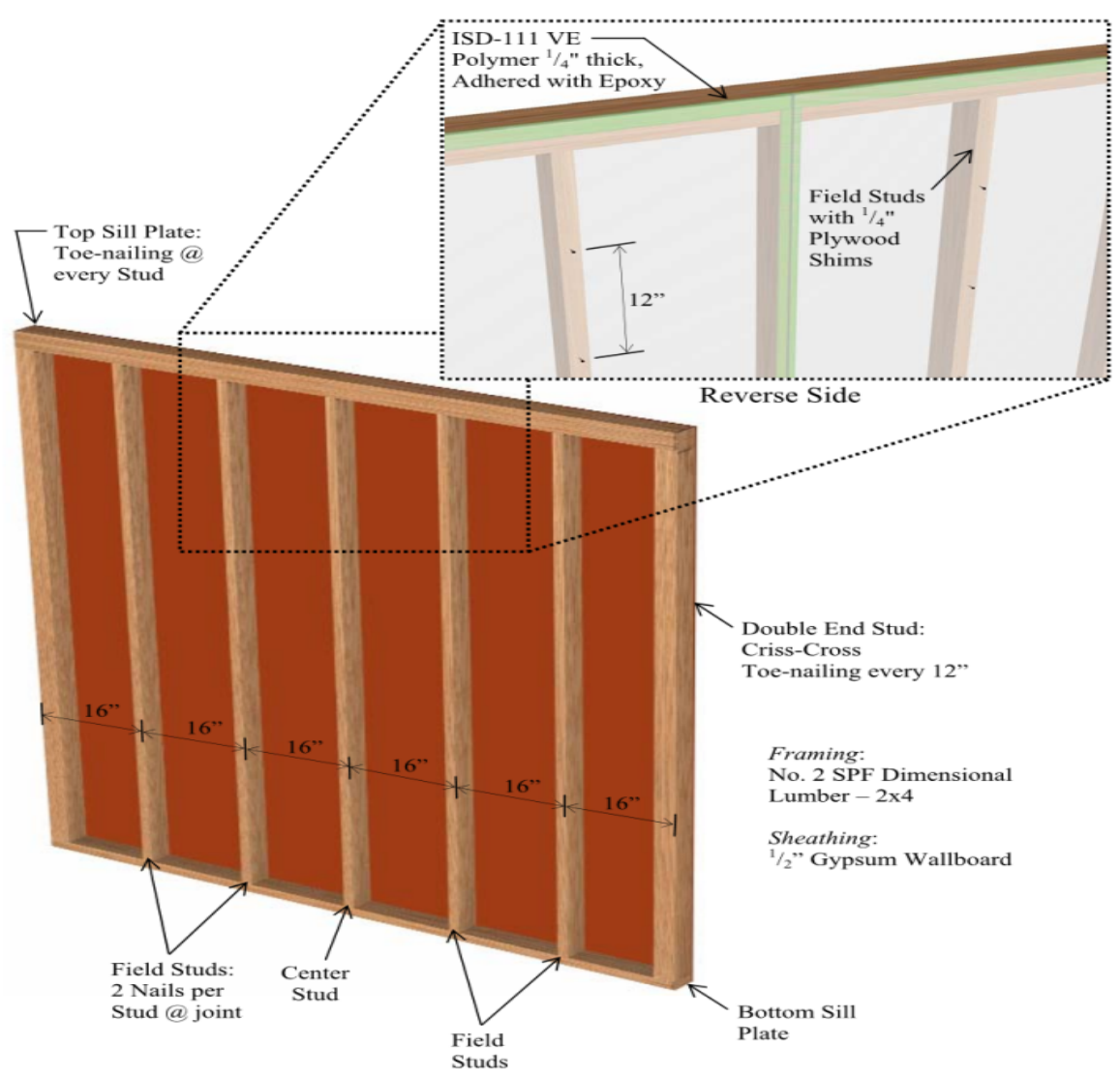


The VEwalls used ISD-111 VE polymer manufactured by $3 \mathrm{M}$ that is isotropic and has properties that simultaneously exhibit those of a viscous fluid as well as a solid [14-18]. Therefore, its dynamic response is dominated by a stiffness force (function of displacement) and a damping force (function of velocity). The perimeter of the sheathing panels was fastened to the framing by adhering the VE material between the two. Viscoelastic material was located along the top and bottom sill plates as well as the end and center studs. Strips of VE polymer were initially adhered to the stud framing using high strength epoxy. The plastic backing was removed from the strips and epoxy was applied to the sheathing side of the polymer and a sheathing panel was laid on top of it. Screws were immediately installed along the perimeter with a spacing of 12 " to produce a clamping effect as recommended by the epoxy manufacturer. After 24 hours, the perimeter screws were removed. Screwed sheathing connections along the field studs typically undergo little if any damage because the relative displacement between the sheathing and the field studs is typically small. Hence, a 1/4 in. shim was used in lieu of VE material. Joint tape and compound were applied between the two gypsum panels 24 hours prior to testing for both types of shear wall specimens.

\section{Experimental Setup and Procedure}

The wall specimen is installed between two load-resisting self-reacting frames, and is anchored to a lower support channel. Figure 3 shows the shear wall test frame with a GYPwall specimen installed. A horizontal displacement load was distributed along the top sill plate, while the bottom sill plate was fully braced with anchor bolts and cover plates. Lateral load is applied via a 20,000 lb hydraulic actuator with a guide beam that is bolted to the top of the specimen. Bearing rollers, oriented perpendicular to the direction of loading, were installed along the top sill plate as lateral bracing. Uplift was restrained at the end studs through the use of TDX5 hold downs manufactured by USP Connectors.

Figure 3. Shearwall test frame with specimen installed.

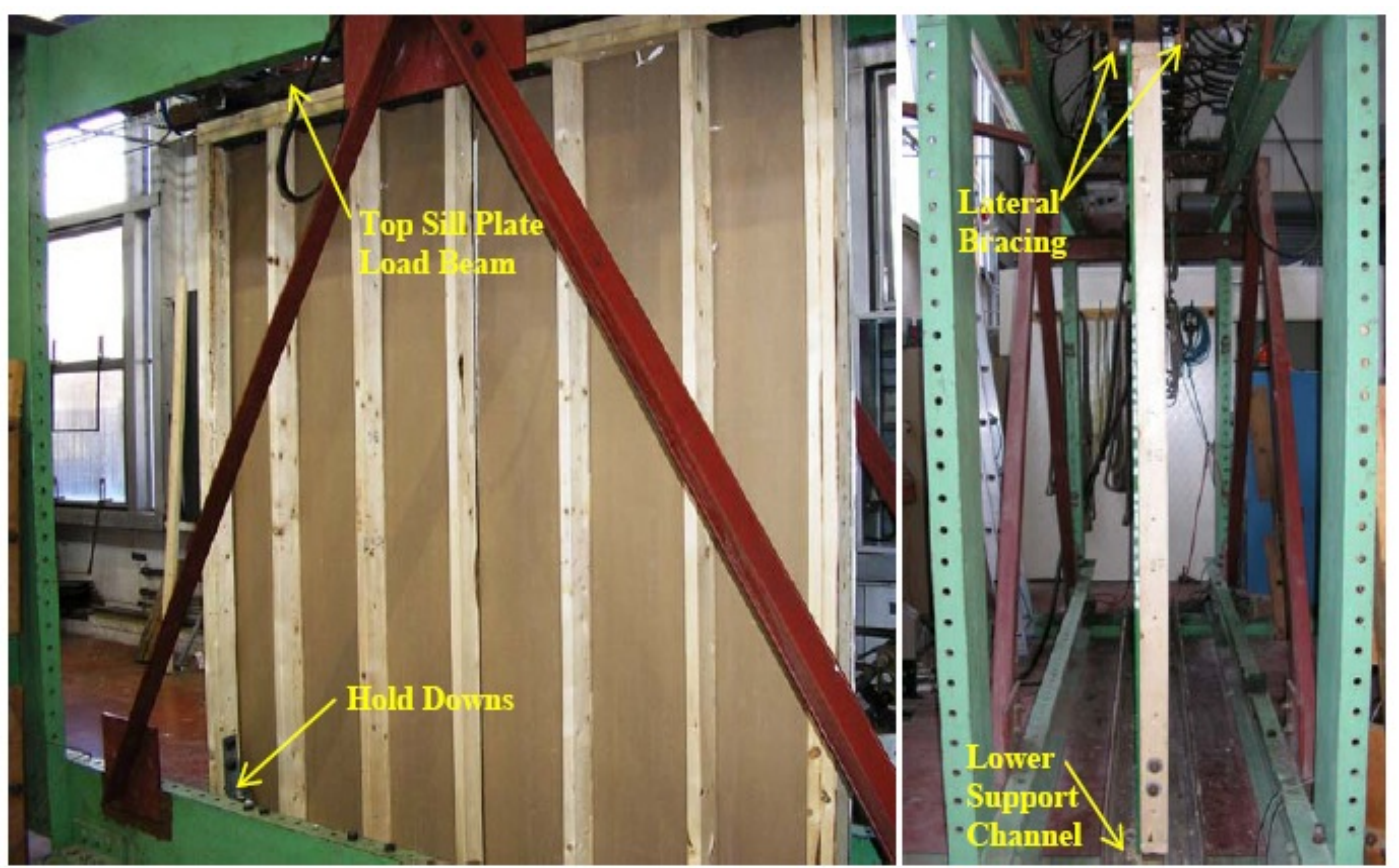


The data acquisition and control system simultaneously provided the hydraulic actuator with the displacement test sequence while recording measurements during its execution. Five channels of data were recorded including load from the actuator, lateral displacement of the actuator located at the top of the wall, lateral displacement at the other top corner of the wall via an independent cable potentiometer, and uplift displacements at each corner.

All shear wall specimens were subjected to the recommended CUREE displacement protocol for shear walls at a frequency of $1.0 \mathrm{~Hz}$ [19]. The maximum displacement was 2.86". The shear wall loading protocol is plotted in Figure 4. This protocol, designed to mimic the effects of an earthquake, is split into three components: initiation cycles, primary cycles, and secondary cycles. The initiation cycles simulate the cyclic loading that structures typically undergo. After the initiation cycles are sets of one primary cycle followed by several secondary cycles, which simulate earthquake loading. The primary cycles have larger amplitudes than their preceding secondary cycles, and simulate major events. Shear walls were subjected to a total of 37 cycles.

Figure 4. Shearwall loading protocol.

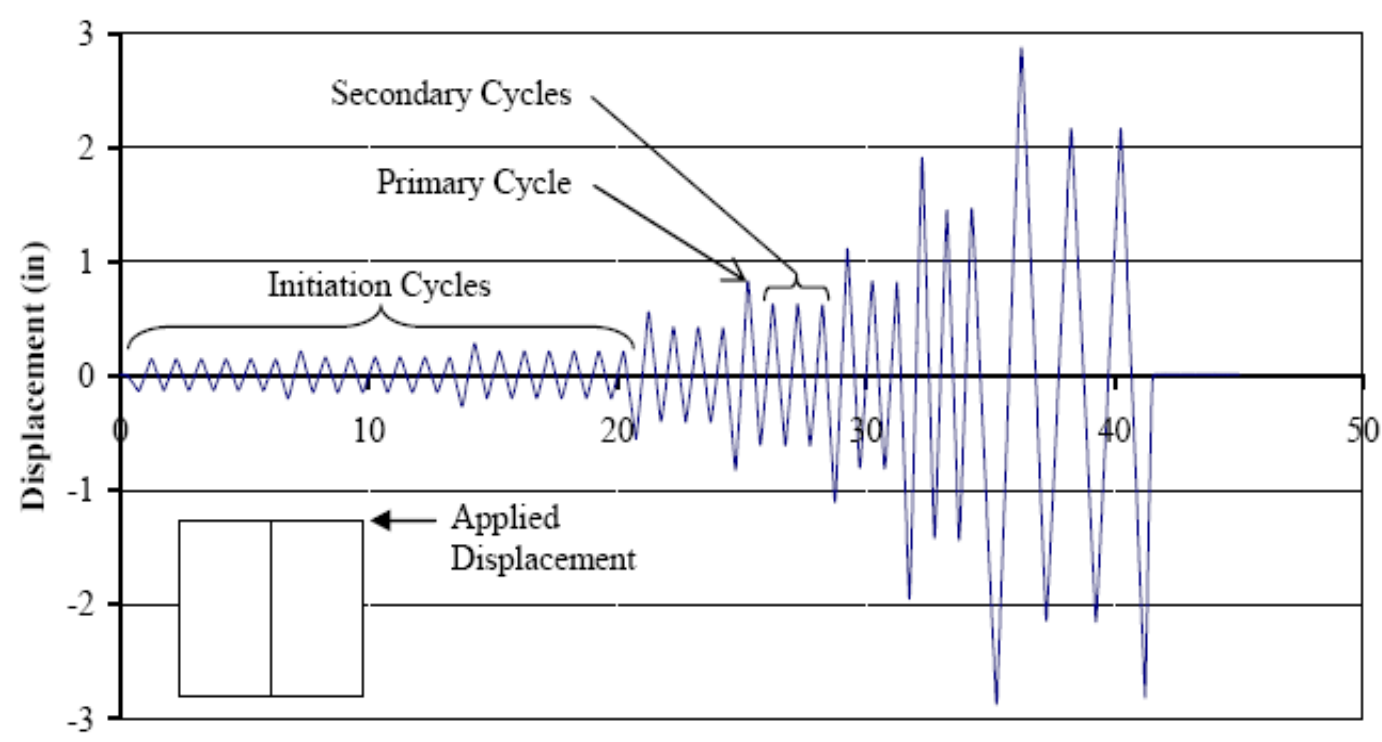

Time (sec)

\section{Hysteresis Results}

A typical hysteresis (load-displacement) plot for the four OSBwalls tested is presented in Figure 5. The area inside a single cycle hysteresis is defined as the energy dissipated in that cycle. The slope of the loop is defined as the stiffness [20-22]. The OSBwall hysteresis is characterized by a pinched region at small displacements and load degradation at constant amplitude cycling. 
Figure 5. Hysteresis plot for OSBwall 1.

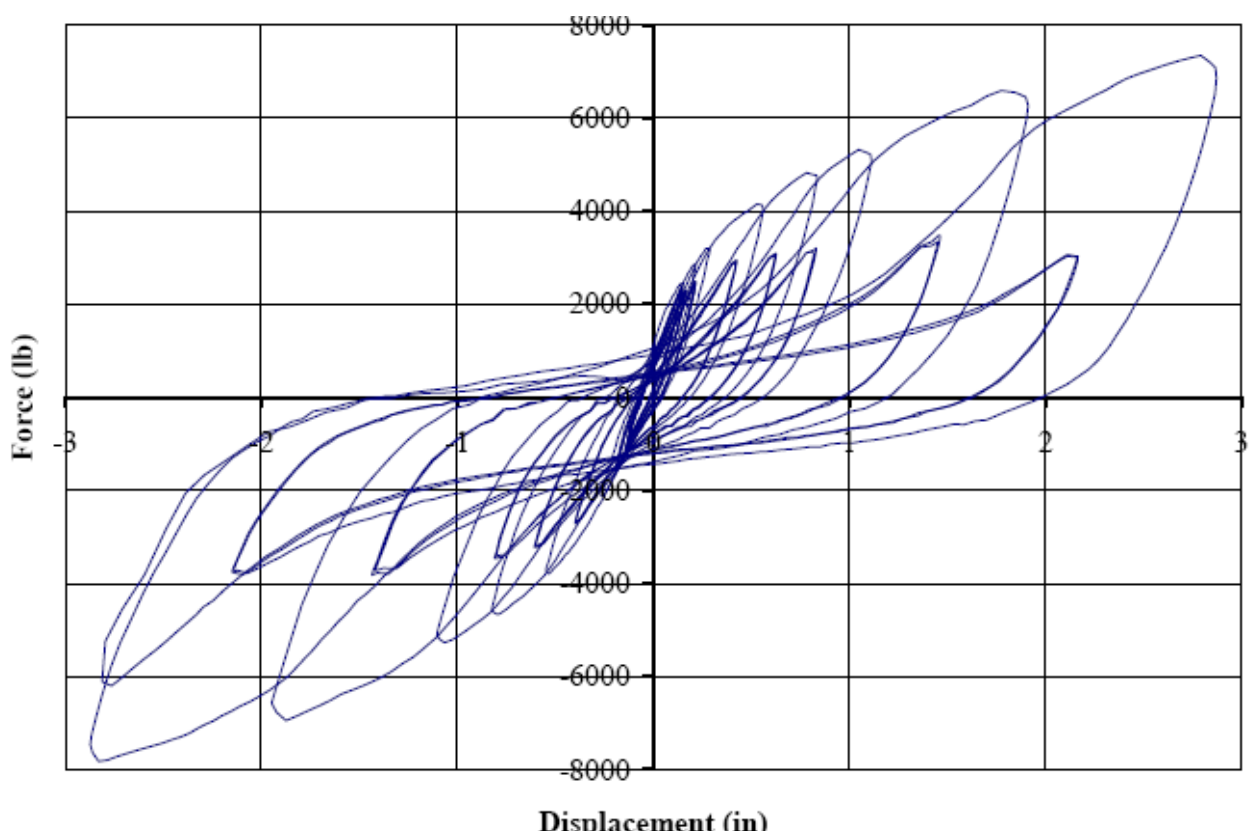

A typical hysteresis plot for one of the three GYPwall specimens tested is shown in Figure 6. Qualitatively, the hysteresis plots for the gypsum shear walls take on some but not all characteristics of the OSB walls. The most prominent characteristic is the extreme degradation between primary and secondary cycles, marked by reduced area of the hysteresis loops. The pinched region is also well-pronounced, and has virtually no thickness near the origin. However, certain characteristics of the hysteresis plots are unique to these shear walls. The primary cycles exhibit loops that are smooth and rounded, without sharp peaks or corners. This differs from both OSB shear walls and baseline gypsum connections and is an unanticipated response to the ramped loading defined by the recommended CUREE displacement protocol.

Figure 6. Hysteresis plot for GYPwall 3.

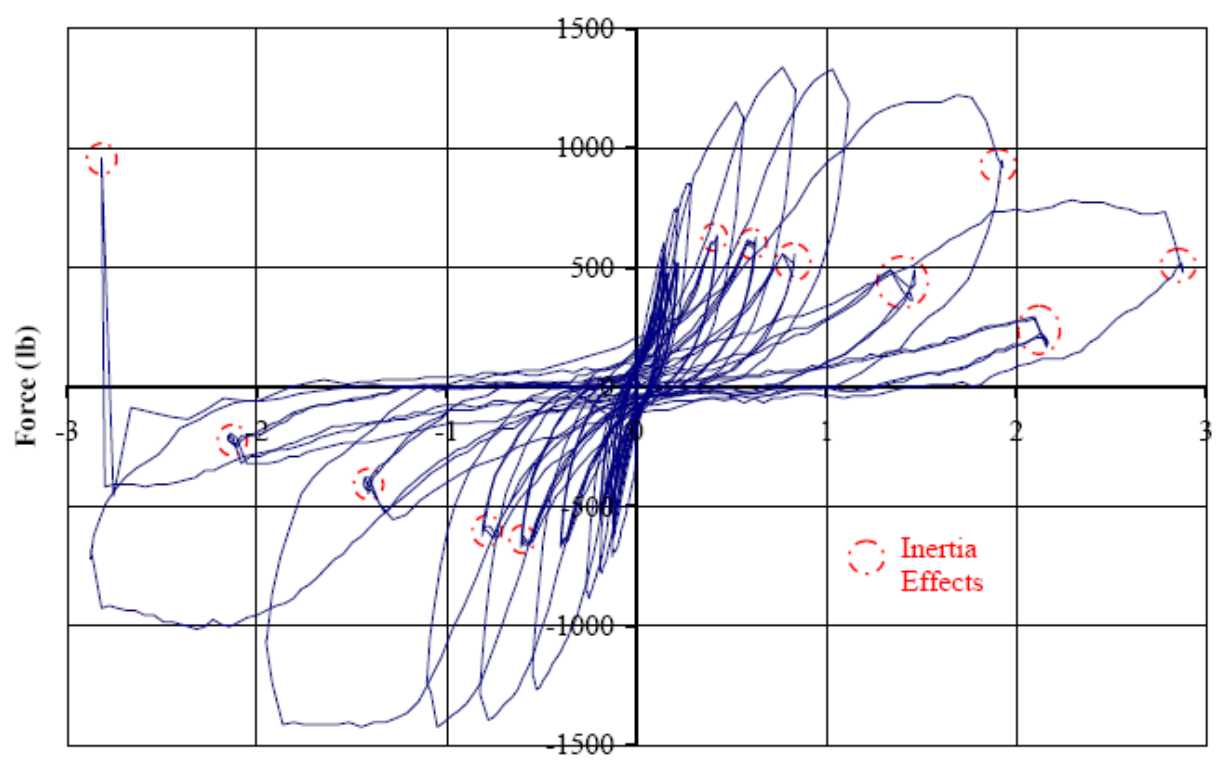

Displacement (in) 
The sudden change in motion caused by ramped loading often produces abrupt changes in direction of the hysteresis plots, which are not present in the primary cycles of the gypsum shear walls. They are, however, present in the secondary cycles, which exhibit abnormalities at the extreme displacements. These abnormalities are most likely caused by inertia effects imposed by the mass of the load beam that rests atop the shear wall specimen during testing. These effects are highlighted by the red dashed circles in Figure 6. With ramped loading, the actuator changes direction very quickly, requiring maximum acceleration from the hydraulic system. This acceleration is applied to the steel load beam, which contains a significant mass and is bolted to the top of the shear wall. The inertia forces caused by the apparatus are typically neglected because they represent a slight percentage of the dynamic response of most shear walls. However, gypsum shear walls provide very weak responses, so the inertia effects represent a greater percentage of the total response.

Three VEwalls were tested with very similar results. A typical dynamic response is presented in Figure 7. Investigation of the hysteresis shows that the pinched region has been eliminated and there is very little degradation between cycles. Hysteresis loops for the VE gypsum shear walls appear more as parallelograms and not ovals, similar to a hysteresis loop of a VE damper. This can be attributed to the loading protocol rather than the type of specimen. The ramped loading used for the shear wall protocol consists of regions of constant velocity. When a damper is subjected to a constant velocity it produces a constant damping force, producing a hysteresis loop that resembles a rectangle. If a spring is assembled in parallel to the damper, then the rectangular hysteresis loop would be projected onto the linear response of the spring. It is significant to note that all three VEwall specimens failed after 31 cycles.

Figure 7. Hysteresis plot for VEwall 3.

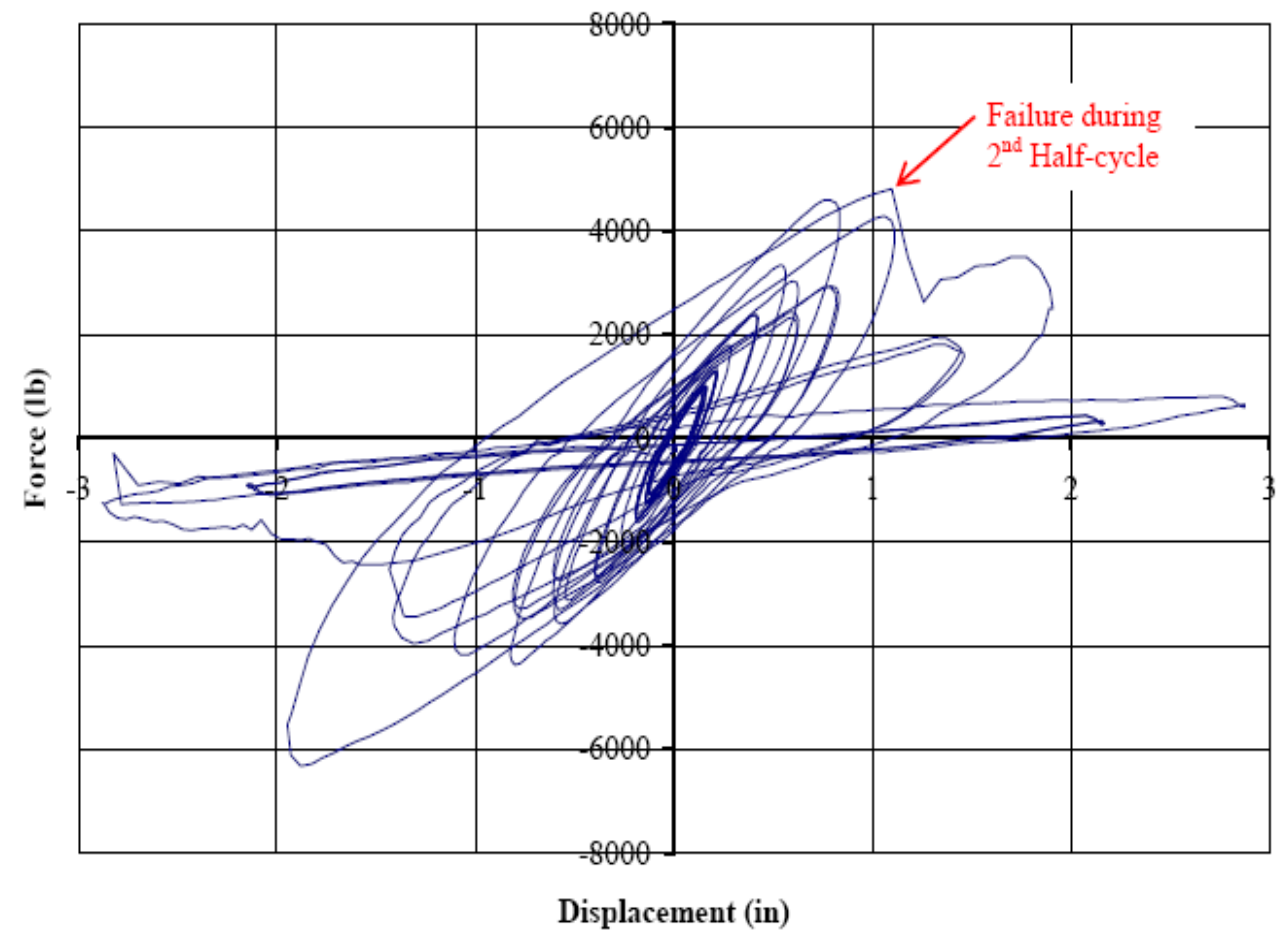

Figures 5-7 provide a detailed view of the cyclic response for each wall. The displacement scales for each plot are identical; however, to view the detail of the plot the load scales are significantly 
different. Figure 8 presents the three hysteresis responses shown in Figures 5-7 plotted to the same load scale. It is clear that the response of each of these wall systems to the simulated earthquake cyclic loading is dramatically different. In comparing the GYPwall with the OSBwall, both have similar forms; however, the GYPwall clearly provides substantially less load resistance than the OSBwall. The VEwall has a drastically different response as indicated by the shape of the hysteresis loops and also has a much greater cyclic load resistance when compared to the GYPwall. A general comparison of the cyclic behavior of these connections and walls has been reported [20]. Based on these significant differences in behavior between the three wall types an in- depth analysis of the energy dissipation and stiffness characteristics on a per cycle and cumulative basis is warranted. This detailed analysis is provided in the following sections.

Figure 8. Representative hystereses plotted to the same scale.

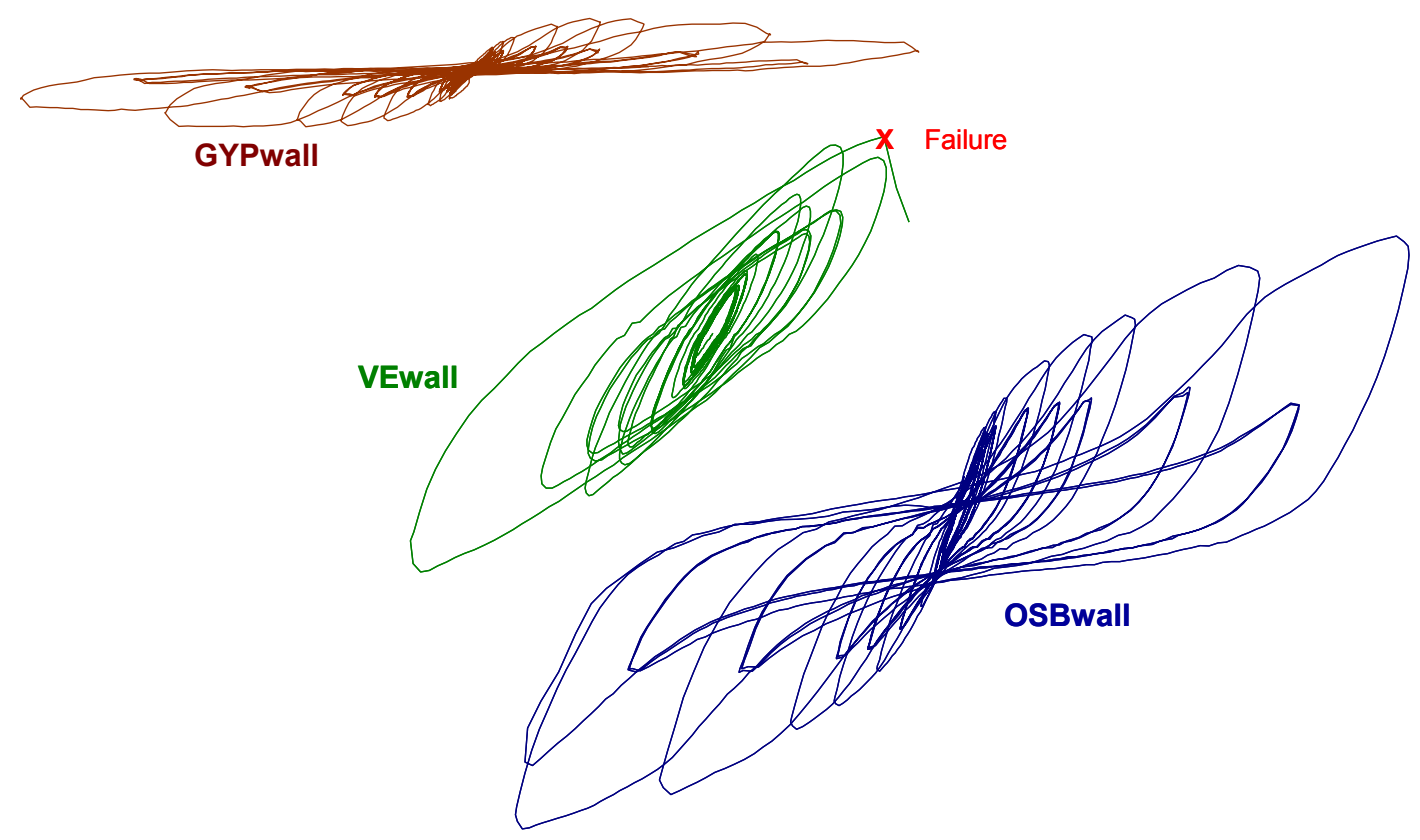

\section{Energy Dissipation Results}

The energy dissipation, $\mathrm{E}_{\mathrm{D}}$, of the wall is calculated per cycle as the area enclosed in one loop. Tables 1-3 present the energy dissipation data for the OSBwalls, the GYPwalls and VEwalls respectively. The cycle number, lateral wall displacement, individual test results, averages, and standard deviations are included. Cycles are grouped in sets according to cycle displacement. The first cycle within each set is the primary cycle, and the following cycles of that set are the secondary cycles. 
Table 1. Energy Dissipation (lb-in) of OSBwalls.

\begin{tabular}{|c|c|c|c|c|c|c|c|}
\hline Cycle & Displacement (in) & OSBwall1 & OSBwall2 & OSBwall3 & OSBwall4 & Average & Standard deviations \\
\hline 1 & 0.14 & 124.4 & 174.8 & 163.8 & 109.1 & 143.1 & 31.3 \\
\hline 2 & 0.14 & 127.9 & 157.5 & 126.4 & 100.2 & 128 & 23.4 \\
\hline 3 & 0.14 & 125.5 & 153.5 & 127.7 & 98.9 & 126.4 & 22.3 \\
\hline 4 & 0.14 & 122.6 & 145.5 & 108 & 96.6 & 118.2 & 21.1 \\
\hline 5 & 0.14 & 121.4 & 151.4 & 113.1 & 97.7 & 120.9 & 22.6 \\
\hline 6 & 0.14 & 119.9 & 146.1 & 111.5 & 92.1 & 117.4 & 22.4 \\
\hline 7 & 0.21 & 291 & 313.6 & 266 & 244.1 & 278.7 & 30.1 \\
\hline 8 & 0.15 & 163.9 & 192.9 & 141.1 & 136.1 & 158.5 & 25.9 \\
\hline 9 & 0.15 & 158.9 & 185 & 137.8 & 130.3 & 153 & 24.5 \\
\hline 10 & 0.15 & 155.5 & 169.6 & 134.1 & 128.8 & 147 & 19 \\
\hline 11 & 0.15 & 157.2 & 174.9 & 133.5 & 129.2 & 148.7 & 21.4 \\
\hline 12 & 0.15 & 155.2 & 178.4 & 131.9 & 131.6 & 149.3 & 22.4 \\
\hline 13 & 0.15 & 152.6 & 179.3 & 136.5 & 127.2 & 148.9 & 22.8 \\
\hline 14 & 0.28 & 478.4 & 486.3 & 428.3 & 435.4 & 457.1 & 29.5 \\
\hline 15 & 0.2 & 275.1 & 297 & 216.1 & 246.3 & 258.6 & 35.1 \\
\hline 16 & 0.2 & 266.2 & 273.9 & 215.9 & 233.8 & 247.5 & 27.3 \\
\hline 17 & 0.2 & 262 & 272.2 & 223.8 & 231.6 & 247.4 & 23.4 \\
\hline 18 & 0.2 & 261.7 & 273.7 & 199.4 & 228.6 & 240.8 & 33.6 \\
\hline 19 & 0.2 & 262.6 & 263.5 & 207.9 & 225.9 & 240 & 27.6 \\
\hline 20 & 0.2 & 258.4 & 267.7 & 224.4 & 229.8 & 245.1 & 21.2 \\
\hline 21 & 0.55 & 1813.5 & 1714.2 & 1457.2 & 1898.7 & 1720.9 & 191.3 \\
\hline 22 & 0.41 & 807.6 & 749.1 & 679.9 & 838 & 768.7 & 69.7 \\
\hline 23 & 0.41 & 786.4 & 730.6 & 631.1 & 802.7 & 7373.7 & 77.5 \\
\hline 24 & 0.41 & 751.4 & 742.7 & 604.7 & 792.7 & 722.9 & 81.7 \\
\hline 25 & 0.83 & 3392.8 & 3074.6 & 2631.6 & 3536.3 & 3158.8 & 401 \\
\hline 26 & 0.61 & 1458.4 & 1288.4 & 1113.5 & 1580.3 & 1360.1 & 203.4 \\
\hline 27 & 0.61 & 1392.2 & 1265.9 & 1041.1 & 1473.1 & 1293.1 & 188.4 \\
\hline 28 & 0.61 & 1362.2 & 1266.2 & 965.8 & 1440.3 & 1258.6 & 207.8 \\
\hline 29 & 1.11 & 5021.2 & 4576 & 3962.3 & 5135 & 4673.6 & 532 \\
\hline 30 & 0.82 & 2206.9 & 1991.7 & 1654 & 2307.2 & 2040 & 289 \\
\hline 31 & 0.82 & 2090.5 & 1981.8 & 1488.1 & 2167.5 & 1932 & 305.5 \\
\hline 32 & 1.93 & 13439.5 & 13016 & 11687.7 & 13513.9 & 12914.3 & 846.6 \\
\hline 33 & 1.44 & 4990.1 & 4683 & 3954.7 & 4763.9 & 4597.9 & 448.1 \\
\hline 34 & 1.44 & 4582.3 & 4497 & 3785.2 & 4394.2 & 4314.7 & 361.2 \\
\hline 35 & 2.87 & 21142.2 & 21448.7 & 19598.9 & 20691.9 & 20720.4 & 809.7 \\
\hline 36 & 2.15 & 7625.3 & 7598.2 & 6475.9 & 6583.5 & 7070.7 & 626.4 \\
\hline 37 & 2.15 & 7050.5 & 6979.5 & 6065.7 & 5811.9 & 6476.9 & 630.6 \\
\hline \multicolumn{2}{|r|}{ Total } & 83953.5 & 82060.2 & 71344.6 & 81184.4 & 79635.7 & 5646.9 \\
\hline
\end{tabular}


Table 2. Energy Dissipation (lb-in) of GYPwalls.

\begin{tabular}{|c|c|c|c|c|c|c|}
\hline Cycle & Displacement (in) & GYPwall1 & GYPwall2 & GYPwall3 & Average & Standard deviation \\
\hline 1 & 0.14 & 69.7 & 101.0 & 95.0 & 88.6 & 16.6 \\
\hline 2 & 0.14 & 49.0 & 60.1 & 63.4 & 57.5 & 7.5 \\
\hline 3 & 0.14 & 43.7 & 52.4 & 61.7 & 52.6 & 9.0 \\
\hline 4 & 0.14 & 40.9 & 49.8 & 55.3 & 48.6 & 7.3 \\
\hline 5 & 0.14 & 40.6 & 48.3 & 55.4 & 48.1 & 7.4 \\
\hline 6 & 0.14 & 37.6 & 45.0 & 50.3 & 44.3 & 6.4 \\
\hline 7 & 0.21 & 105.6 & 112.4 & 122.7 & 113.6 & 8.6 \\
\hline 8 & 0.15 & 46.4 & 50.3 & 65.5 & 54.1 & 10.1 \\
\hline 9 & 0.15 & 40.7 & 54.7 & 55.1 & 50.2 & 8.2 \\
\hline 10 & 0.15 & 43.1 & 49.9 & 56.9 & 50.0 & 6.9 \\
\hline 11 & 0.15 & 38.4 & 44.6 & 54.7 & 45.9 & 8.2 \\
\hline 12 & 0.15 & 39.4 & 49.0 & 57.5 & 48.6 & 9.0 \\
\hline 13 & 0.15 & 40.4 & 48.1 & 52.4 & 47.0 & 6.1 \\
\hline 14 & 0.28 & 162.2 & 158.9 & 180.0 & 167.0 & 11.3 \\
\hline 15 & 0.2 & 65.1 & 74.5 & 84.3 & 74.6 & 9.6 \\
\hline 16 & 0.2 & 60.7 & 67.3 & 79.2 & 69.1 & 9.3 \\
\hline 17 & 0.2 & 55.7 & 64.8 & 74.6 & 65.1 & 9.4 \\
\hline 18 & 0.2 & 55.4 & 62.8 & 73.6 & 63.9 & 9.2 \\
\hline 19 & 0.2 & 53.8 & 61.6 & 71.6 & 62.3 & 8.9 \\
\hline 20 & 0.2 & 54.0 & 63.3 & 71.1 & 62.8 & 8.5 \\
\hline 21 & 0.55 & 628.8 & 616.7 & 621.9 & 622.4 & 6.1 \\
\hline 22 & 0.41 & 160.8 & 169.9 & 191.0 & 173.9 & 15.5 \\
\hline 23 & 0.41 & 142.2 & 150.3 & 166.9 & 153.1 & 12.6 \\
\hline 24 & 0.41 & 137.0 & 149.6 & 155.3 & 147.3 & 9.4 \\
\hline 25 & 0.83 & 900.4 & 967.0 & 959.3 & 942.2 & 36.4 \\
\hline 26 & 0.61 & 227.4 & 286.1 & 275.2 & 262.9 & 31.2 \\
\hline 27 & 0.61 & 178.1 & 224.6 & 230.8 & 211.1 & 28.8 \\
\hline 28 & 0.61 & 167.2 & 210.7 & 208.1 & 195.3 & 24.4 \\
\hline 29 & 1.11 & 1056.6 & 1216.1 & 1200.7 & 1157.8 & 88.0 \\
\hline 30 & 0.82 & 260.9 & 329.2 & 310.5 & 300.2 & 35.3 \\
\hline 31 & 0.82 & 217.6 & 264.3 & 267.7 & 249.8 & 28.0 \\
\hline 32 & 1.93 & 2492.0 & 2608.4 & 2851.5 & 2650.6 & 183.4 \\
\hline 33 & 1.44 & 377.3 & 500.5 & 544.3 & 474.0 & 86.6 \\
\hline 34 & 1.44 & 271.8 & 358.6 & 417.6 & 349.3 & 73.3 \\
\hline 35 & 2.87 & 2307.8 & 2188.0 & 2713.5 & 2403.1 & 275.4 \\
\hline 36 & 2.15 & 378.1 & 474.8 & 510.9 & 454.6 & 68.6 \\
\hline 37 & 2.15 & 322.8 & 370.5 & 385.7 & 359.7 & 32.8 \\
\hline \multicolumn{2}{|r|}{ Total } & 11369.3 & 12403.7 & 13490.9 & 12421.3 & 1060.9 \\
\hline
\end{tabular}


Table 3. Energy Dissipation (lb-in) of VEwalls.

\begin{tabular}{|c|c|c|c|c|c|c|}
\hline Cycle & Displacement (in) & VEwall1 & VEwall2 & VEwall3 & Average & Standard. deviation \\
\hline 1 & 0.14 & 147.7 & 150.0 & 135.4 & 144.4 & 7.9 \\
\hline 2 & 0.14 & 150.6 & 150.9 & 136.0 & 145.8 & 8.5 \\
\hline 3 & 0.14 & 146.8 & 151.1 & 138.5 & 145.5 & 6.4 \\
\hline 4 & 0.14 & 148.4 & 147.8 & 139.7 & 145.3 & 4.8 \\
\hline 5 & 0.14 & 145.5 & 147.9 & 140.0 & 144.5 & 4.0 \\
\hline 6 & 0.14 & 149.3 & 152.2 & 136.6 & 146.0 & 8.3 \\
\hline 7 & 0.21 & 325.8 & 332.7 & 311.4 & 323.3 & 10.9 \\
\hline 8 & 0.15 & 192.6 & 195.2 & 182.9 & 190.2 & 6.5 \\
\hline 9 & 0.15 & 185.0 & 187.0 & 178.0 & 183.3 & 4.7 \\
\hline 10 & 0.15 & 188.1 & 187.6 & 175.6 & 183.8 & 7.1 \\
\hline 11 & 0.15 & 183.6 & 183.8 & 178.2 & 181.9 & 3.2 \\
\hline 12 & 0.15 & 186.0 & 188.7 & 175.4 & 183.4 & 7.0 \\
\hline 13 & 0.15 & 188.5 & 185.4 & 176.7 & 183.5 & 6.2 \\
\hline 14 & 0.28 & 563.4 & 575.8 & 546.3 & 561.8 & 14.8 \\
\hline 15 & 0.2 & 335.4 & 337.1 & 313.7 & 328.7 & 13.0 \\
\hline 16 & 0.2 & 326.1 & 325.7 & 315.5 & 322.4 & 6.0 \\
\hline 17 & 0.2 & 324.9 & 324.1 & 311.7 & 320.2 & 7.4 \\
\hline 18 & 0.2 & 324.7 & 328.0 & 312.9 & 321.9 & 8.0 \\
\hline 19 & 0.2 & 323.4 & 322.0 & 312.3 & 319.2 & 6.1 \\
\hline 20 & 0.2 & 331.5 & 332.4 & 319.3 & 327.7 & 7.3 \\
\hline 21 & 0.55 & 2114.5 & 2307.8 & 2021.7 & 2148.0 & 146.0 \\
\hline 22 & 0.41 & 1187.6 & 1151.1 & 1158.1 & 1165.6 & 19.4 \\
\hline 23 & 0.41 & 1171.7 & 1136.6 & 1145.4 & 1151.2 & 18.3 \\
\hline 24 & 0.41 & 1200.4 & 1157.4 & 1174.9 & 1177.6 & 21.6 \\
\hline 25 & 0.83 & 4561.3 & 4328.4 & 4249.7 & 4379.8 & 162.1 \\
\hline 26 & 0.61 & 2198.9 & 2382.1 & 2298.5 & 2293.2 & 91.7 \\
\hline 27 & 0.61 & 2070.4 & 2344.7 & 2209.4 & 2208.2 & 137.1 \\
\hline 28 & 0.61 & 2084.5 & 2350.8 & 2043.0 & 2159.4 & 167.0 \\
\hline 29 & 1.11 & 6062.3 & 7072.2 & 5931.2 & 6355.3 & 624.4 \\
\hline 30 & 0.82 & 3535.6 & 3709.7 & 3477.2 & 3574.2 & 121.0 \\
\hline 31 & 0.82 & 3518.3 & 3595.1 & 3435.1 & 3516.2 & 80.0 \\
\hline 32 & 1.93 & FAILED & FAILED & FAILED & - & - \\
\hline 33 & 1.44 & - & - & - & - & - \\
\hline 34 & 1.44 & - & - & - & - & - \\
\hline 35 & 2.87 & - & - & & - & - \\
\hline 36 & 2.15 & - & - & & - & - \\
\hline 37 & 2.15 & - & - & & - & - \\
\hline \multicolumn{2}{|r|}{ Total } & 34573.3 & 36441.4 & 33780.1 & 34931.6 & 1366.3 \\
\hline
\end{tabular}

The relationship between energy dissipation and cycle number for all wall specimens is presented in a graphical format in Figure 9. Trend lines, representing the average energy dissipation, are plotted for each type of wall. Error bars are plotted along the trend lines to illustrate the standard deviation within the data at each cycle. Figure 10 presents the total energy dissipated through a given cycle for each wall type. Similar 
to Figure 9, trend lines, representing the average, are plotted for each wall specimen and error bars are plotted along the trend lines to illustrate the standard deviation within the data at each cycle.

Figure 9. Average energy dissipation vs. cycle number for all walls.

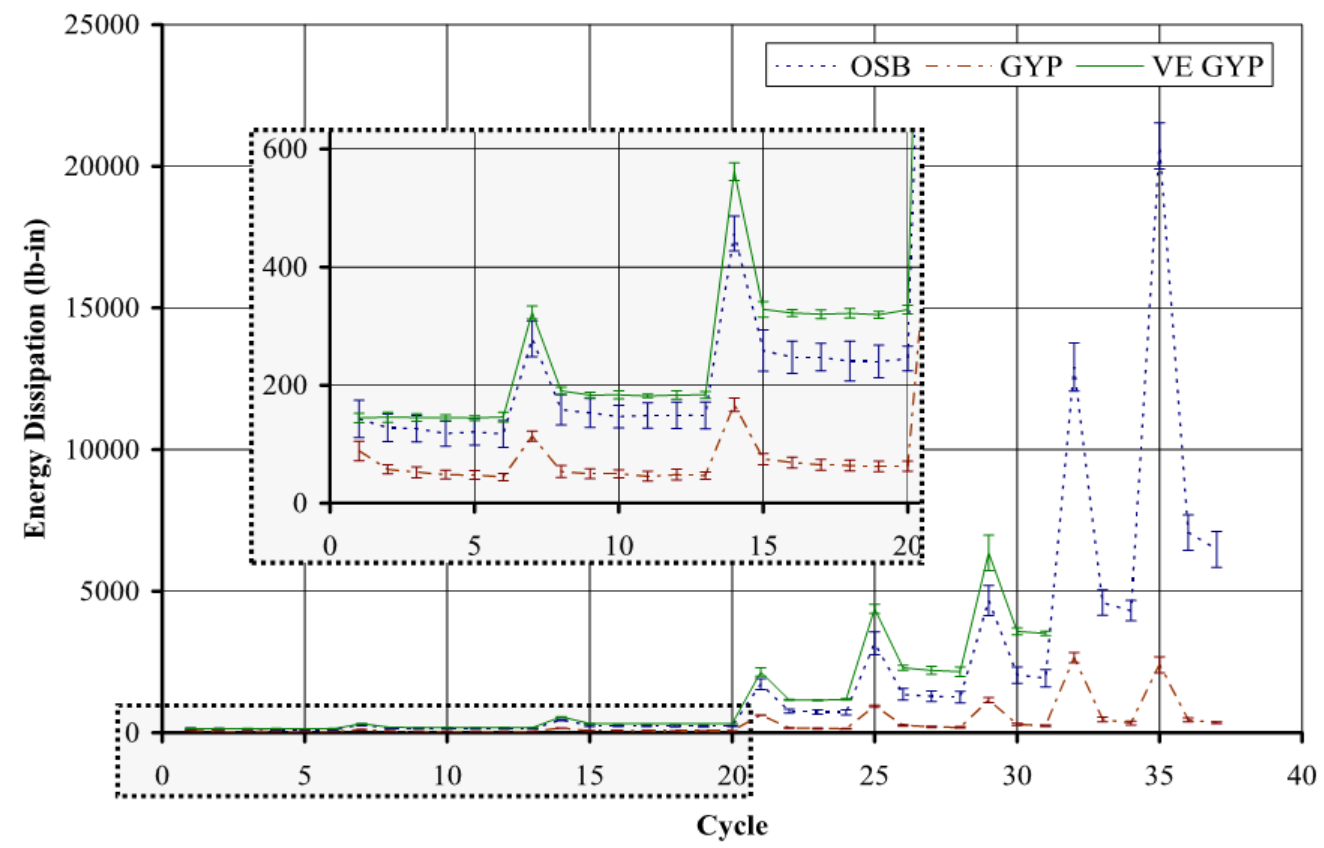

Figure 10. Total energy dissipated for all wall types.

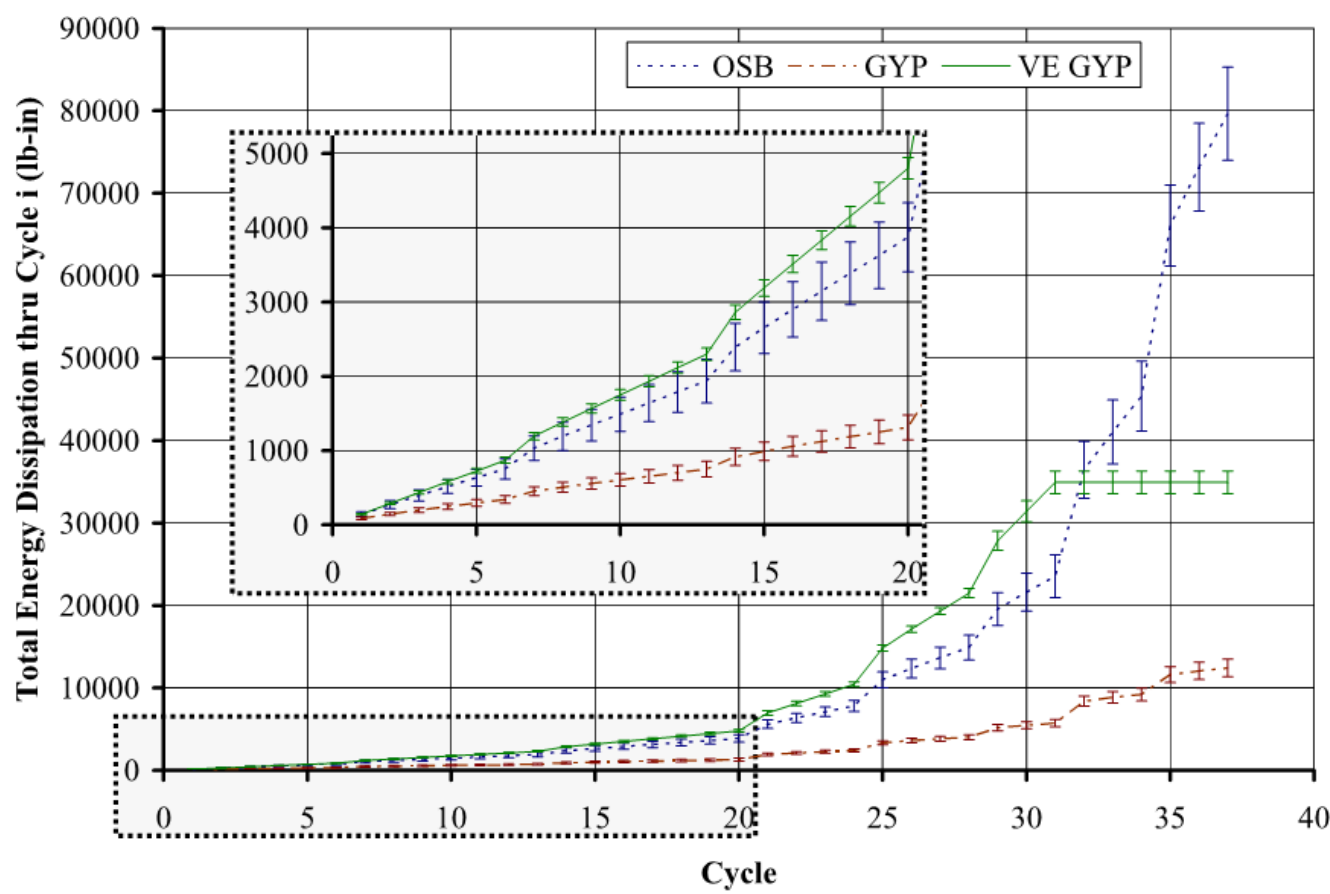

The most prominent characteristic of the energy dissipation trends for the OSBWalls is the dramatic decrease in energy dissipation between primary cycles and secondary cycles. This decrease is somewhat deceiving because it is not entirely due to degradation. From Table 1 it is clear that for the CUREE loading protocol used, the primary cycles have larger displacement amplitudes than their subsequent secondary cycles. This has a significant effect on the area of the hysteresis loops and 
energy dissipation of the secondary cycles. Had the secondary cycles been given the same amplitude as their preceding primary cycles, their hysteresis loops would be longer, their areas would be greater, and their energy dissipation would be higher. Though, it is evident from Figure 5 that there is still significant degradation after primary cycles because the pinched regions are extended for the secondary cycles. Energy dissipated during secondary cycles of constant amplitude remained fairly constant throughout the first 20 cycles. Cycle 1 (0.14") produced $124.4 \mathrm{lb}$-in of energy dissipation, and gradually declined to $119.9 \mathrm{lb}$-in for cycle 6 . Energy dissipated during cycle $8(0.15$ ”) was $163.9 \mathrm{lb}$-in, compared to $152.6 \mathrm{lb}$-in for cycle 13. Cycle 15 (0.20") generated $275.1 \mathrm{lb}$-in of energy dissipation, and decreased to $258.4 \mathrm{lb}$-in. The total energy dissipated by OSBwall1 was 83,953.5 lb-in. The greatest standard deviation was $20.2 \%$ of the average and occurred at cycle $28(0.61$ "). No failures occurred among the four OSB shear walls tested.

For the GYPwalls energy dissipated during secondary cycles of constant amplitude decreased slightly throughout the first 20 cycles. Cycle 1 (0.14") produced an average energy dissipation of $88.6 \mathrm{lb}$-in, and gradually declined to $44.3 \mathrm{lb}$-in for cycle 6 . Energy dissipated during cycle 8 ( $\left.0.15^{\prime \prime}\right)$ was $54.1 \mathrm{lb}$-in on average, compared to $47.0 \mathrm{lb}$-in for cycle 13. Cycle $15(0.20$ ”) generated an average energy dissipation of $74.6 \mathrm{lb}$-in, and decreased to $62.8 \mathrm{lb}$-in.

Among the three gypsum shear wall specimens, GYPwall3 dissipated the most total energy (13,490.9 lb-in), and GYPwall1 dissipated the least total energy (11,369.3 lb-in). The average total energy dissipation was $12,421.3 \mathrm{lb}$-in with a standard deviation of $1,060.9 \mathrm{lb}$-in ( $8.5 \%$ of the average). Generally, GYPwall3 produced the highest values for energy dissipation at each cycle and GYPwall1 produced the lowest values. While consistent, these values are considerably low for a shear wall (approximately $14.8 \%$ of OSBwall1), indicating that gypsum shear walls are not suitable for a major lateral force resisting system. The secondary cycles produced very low energy dissipation such that a single moderate sized seismic event would effectively render a gypsum shear wall incapacitated during future seismic events.

As shown in Table 3 and Figure 9, the values for energy dissipation were very similar for all three VEwall specimens. VEwall2 dissipated the most total energy (36,441.4 lb-in), and VEwall3 produced the lowest total energy dissipation $(33,780.1 \mathrm{lb}$-in). The three specimens averaged a total energy dissipation of 34,931.6 lb-in with a standard deviation of 1,366.3 lb-in (3.9\% of the average). Energy dissipated during secondary cycles of constant amplitude remained virtually constant throughout the first 20 cycles. Cycle 1 ( 0.14 ") produced an average energy dissipation of $144.4 \mathrm{lb}$-in, and increased to $146.0 \mathrm{lb}$-in for cycle 6 . Energy dissipated during cycle 8 ( 0.15 ") was $190.2 \mathrm{lb}$-in on average, compared to $183.5 \mathrm{lb}$-in for cycle 13 . Cycle 15 (0.20") generated an average energy dissipation of $328.7 \mathrm{lb}$-in, and decreased to $327.7 \mathrm{lb}$-in.

The standard deviation was as low as $1.6 \%$ at cycle $23(0.41 \%)$ and as high as $14.0 \%$ at cycle 28 (0.61"). Energy dissipation throughout the first 31 cycles was greater for the VE gypsum walls than for the baseline gypsum walls and OSB walls combined. By comparison, the OSB walls averaged a total energy dissipation of 23,540.7 lb-in (67.4\% of VEwalls) and the baseline gypsum walls averaged a total energy dissipation of 5,729.9 $\mathrm{lb}$-in (16.4\% of VEwalls) throughout the first 31 cycles of displacement. The greatest increases occurred at secondary cycles because there was no inelastic deformation during primary cycles. Since all of the energy was dissipated by the viscoelastic polymer, the VE gypsum shear walls were able to provide a constant, non-degrading supply of energy dissipation. 


\section{Stiffness Results}

The wall stiffness is defined as the slope of the hysteresis plot and is calculated per cycle. Tables 4-6 present the stiffness data for the OSBwalls, the GYPwalls and VEwalls respectively. Similar to the energy dissipation data presented previously, the cycle number, lateral wall displacement, individual test results, averages, and standard deviations are included. Cycles are grouped in sets according to cycle displacement with the first cycle within each set defined as the primary cycle, followed by the secondary cycles. Figure 11 presents the graphical representation of stiffness per cycle for all wall types and Figure 12 highlights the percentage of total stiffness loss per cycle. For Figures 11,12 trend lines, representing the average, are plotted for each wall type and error bars are plotted along the trend lines to illustrate the standard deviation within the data at each cycle.

Figure 11. Average stiffness vs. cycle number for all walls.

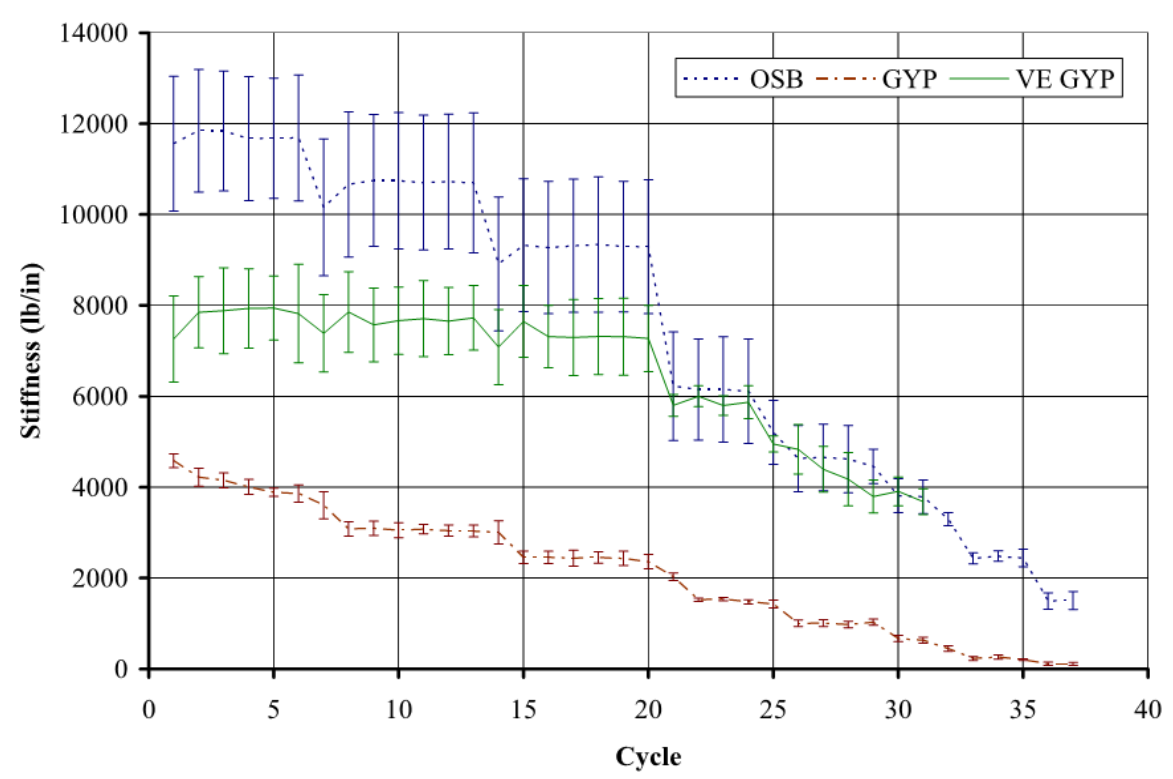

Figure 12. Average stiffness vs. cycle number for GYPwalls.

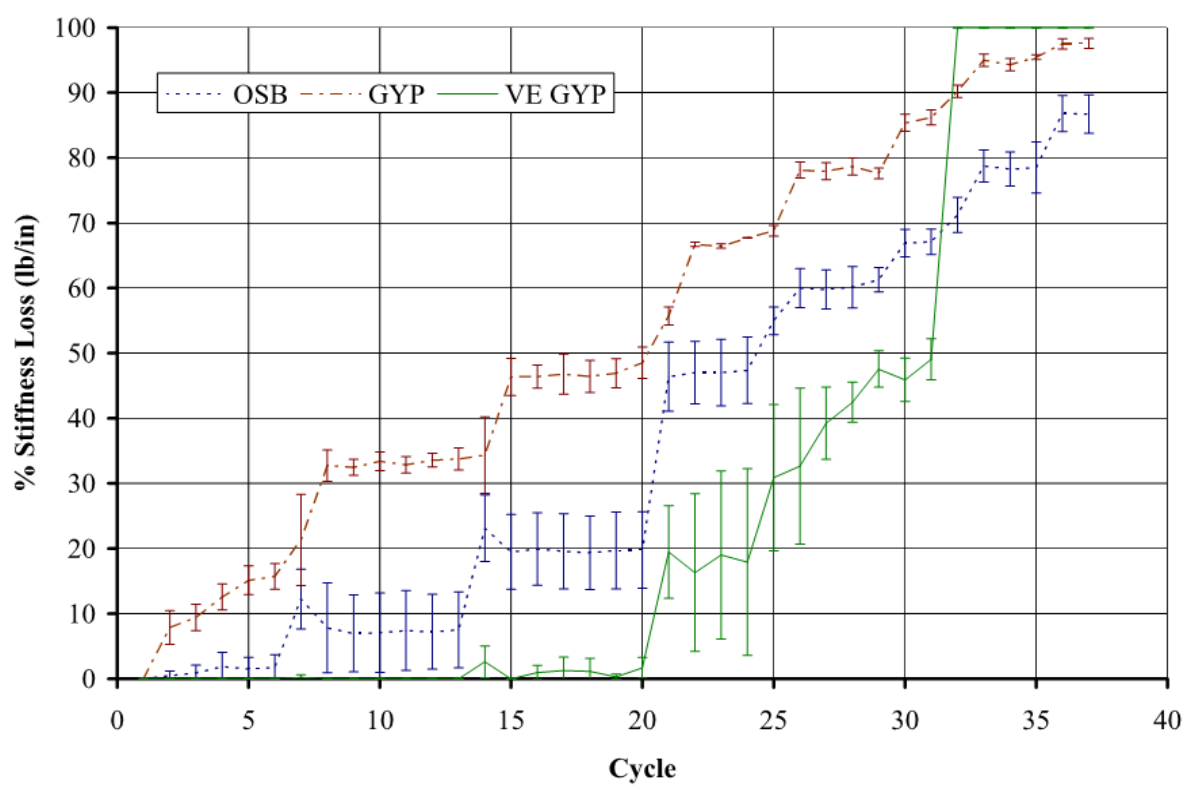


Table 4. Stiffness (lb/in) of OSBwalls.

\begin{tabular}{|c|c|c|c|c|c|c|c|}
\hline Cycle & Displacement (in) & OSBwall1 & OSBwall2 & OSBwall3 & OSBwall4 & Average & Standard. deviation \\
\hline 1 & 0.14 & 11532.2 & 10906.9 & 10175.0 & 13619.0 & 11558.3 & 1481.5 \\
\hline 2 & 0.14 & 11914.3 & 11916.8 & 10125.3 & 13416.6 & 11843.3 & 1346.3 \\
\hline 3 & 0.14 & 12020.0 & 11985.7 & 10070.6 & 13273.7 & 11837.5 & 1321.6 \\
\hline 4 & 0.14 & 11878.3 & 11914.3 & 9803.2 & 13087.2 & 11670.8 & 1365.8 \\
\hline 5 & 0.14 & 11735.3 & 11914.3 & 9926.4 & 13130.8 & 11676.7 & 1321.3 \\
\hline 6 & 0.14 & 11771.0 & 11983.7 & 9818.1 & 13166.7 & 11684.9 & 1387.7 \\
\hline 7 & 0.21 & 10693.3 & 9735.6 & 8322.5 & 11877.9 & 10157.3 & 1504.7 \\
\hline 8 & 0.15 & 10947.0 & 10870.3 & 8491.5 & 12345.2 & 10663.5 & 1598.8 \\
\hline 9 & 0.15 & 11100.0 & 10845.3 & 8783.0 & 12276.5 & 10751.2 & 1452.7 \\
\hline 10 & 0.15 & 11131.6 & 10813.4 & 8714.3 & 12313.0 & 10743.1 & 1498.5 \\
\hline 11 & 0.15 & 11100.0 & 10781.8 & 8682.7 & 12240.4 & 10701.2 & 1484.2 \\
\hline 12 & 0.15 & 11004.2 & 10813.7 & 8746.3 & 12340.1 & 10726.1 & 1484.3 \\
\hline 13 & 0.15 & 11158.6 & 10631.7 & 8650.8 & 12341.4 & 10695.6 & 1539.3 \\
\hline 14 & 0.28 & 9567.9 & 8332.1 & 7182.0 & 10574.0 & 8914.0 & 1474.4 \\
\hline 15 & 0.2 & 9934.1 & 9094.6 & 7414.8 & 10851.5 & 9323.8 & 1460.9 \\
\hline 16 & 0.2 & 9897.4 & 8988.3 & 7397.5 & 10803.9 & 9271.8 & 1452.8 \\
\hline 17 & 0.2 & 9982.3 & 9012.1 & 7417.2 & 10830.2 & 9310.5 & 1464.5 \\
\hline 18 & 0.2 & 9982.3 & 9010.0 & 7441.1 & 10925.5 & 9339.7 & 1487.8 \\
\hline 19 & 0.2 & 10006.1 & 9012.1 & 7417.2 & 10740.9 & 9294.1 & 1437.9 \\
\hline 20 & 0.2 & 9920.9 & 9053.9 & 7366.7 & 10822.1 & 9290.9 & 1472.0 \\
\hline 21 & 0.55 & 6984.3 & 5419.0 & 5015.6 & 7479.7 & 6224.7 & 1192.0 \\
\hline 22 & 0.41 & 6837.5 & 5588.8 & 4873.1 & 7288.5 & 6147.0 & 1112.7 \\
\hline 23 & 0.41 & 6876.0 & 5532.8 & 4846.5 & 7340.7 & 6149.0 & 1158.3 \\
\hline 24 & 0.41 & 6837.4 & 5501.5 & 4818.1 & 7286.9 & 6111.0 & 1148.0 \\
\hline 25 & 0.83 & 5555.2 & 4842.8 & 4428.6 & 5996.5 & 5205.8 & 703.1 \\
\hline 26 & 0.61 & 5064.8 & 4379.4 & 3730.8 & 5359.0 & 4633.5 & 728.5 \\
\hline 27 & 0.61 & 5123.9 & 4315.1 & 3794.7 & 5382.7 & 4654.1 & 731.4 \\
\hline 28 & 0.61 & 5096.7 & 4309.0 & 3721.8 & 5340.6 & 4617.0 & 741.6 \\
\hline 29 & 1.11 & 4579.9 & 4354.7 & 3998.6 & 4897.8 & 4457.7 & 378.6 \\
\hline 30 & 0.82 & 4055.1 & 3739.1 & 3316.6 & 4132.4 & 3810.8 & 370.8 \\
\hline 31 & 0.82 & 4019.4 & 3684.9 & 3314.6 & 4132.9 & 3787.9 & 368.4 \\
\hline 32 & 1.93 & 3326.7 & 3375.8 & 3087.8 & 3399.0 & 3297.3 & 142.9 \\
\hline 33 & 1.44 & 2461.6 & 2566.2 & 2275.3 & 2422.9 & 2431.5 & 120.5 \\
\hline 34 & 1.44 & 2512.1 & 2621.1 & 2345.2 & 2454.9 & 2483.3 & 115.0 \\
\hline 35 & 2.87 & 2491.4 & 2625.6 & 2483.5 & 2168.4 & 2442.2 & 193.9 \\
\hline 36 & 2.15 & 1565.7 & 1674.1 & 1497.4 & 1250.5 & 1496.9 & 179.7 \\
\hline 37 & 2.15 & 1570.3 & 1709.3 & 1507.0 & 1237.0 & 1505.9 & 198.2 \\
\hline
\end{tabular}


Table 5. Stiffness (lb/in) of GYPwalls.

\begin{tabular}{|c|c|c|c|c|c|c|}
\hline Cycle & Displacement (in) & GYPwall1 & GYPwall2 & GYPwall3 & Average & Standard deviation \\
\hline 1 & 0.14 & 4460.4 & 4533.8 & 4752.6 & 4582.3 & 152.0 \\
\hline 2 & 0.14 & 4186.1 & 4043.2 & 4436.4 & 4221.9 & 199.0 \\
\hline 3 & 0.14 & 4114.7 & 4006.3 & 4331.6 & 4150.9 & 165.7 \\
\hline 4 & 0.14 & 3971.4 & 3862.5 & 4186.1 & 4006.7 & 164.7 \\
\hline 5 & 0.14 & 3900.0 & 3792.2 & 3971.6 & 3887.9 & 90.3 \\
\hline 6 & 0.14 & 3790.0 & 3720.8 & 4079.1 & 3863.3 & 190.1 \\
\hline 7 & 0.21 & 3841.4 & 3272.0 & 3696.6 & 3603.3 & 296.0 \\
\hline 8 & 0.15 & 3078.2 & 2925.7 & 3244.0 & 3082.6 & 159.2 \\
\hline 9 & 0.15 & 2989.6 & 3021.5 & 3275.9 & 3095.7 & 156.9 \\
\hline 10 & 0.15 & 2926.1 & 2989.6 & 3244.0 & 3053.2 & 168.2 \\
\hline 11 & 0.15 & 3053.1 & 2989.6 & 3186.1 & 3076.3 & 100.3 \\
\hline 12 & 0.15 & 2989.6 & 2957.7 & 3186.4 & 3044.6 & 123.9 \\
\hline 13 & 0.15 & 3014.1 & 2916.9 & 3174.7 & 3035.3 & 130.2 \\
\hline 14 & 0.28 & 3199.1 & 2718.5 & 3102.8 & 3006.8 & 254.3 \\
\hline 15 & 0.2 & 2519.8 & 2303.5 & 2551.8 & 2458.4 & 135.1 \\
\hline 16 & 0.2 & 2432.6 & 2337.9 & 2599.7 & 2456.7 & 132.5 \\
\hline 17 & 0.2 & 2466.0 & 2252.5 & 2599.7 & 2439.4 & 175.1 \\
\hline 18 & 0.2 & 2495.7 & 2314.0 & 2551.8 & 2453.8 & 124.3 \\
\hline 19 & 0.2 & 2408.6 & 2290.0 & 2599.7 & 2432.8 & 156.2 \\
\hline 20 & 0.2 & 2351.7 & 2207.7 & 2519.5 & 2359.6 & 156.1 \\
\hline 21 & 0.55 & 2034.4 & 1942.0 & 2109.2 & 2028.5 & 83.7 \\
\hline 22 & 0.41 & 1498.2 & 1510.0 & 1564.8 & 1524.3 & 35.6 \\
\hline 23 & 0.41 & 1505.7 & 1529.4 & 1576.7 & 1537.3 & 36.2 \\
\hline 24 & 0.41 & 1443.2 & 1462.7 & 1533.9 & 1479.9 & 47.8 \\
\hline 25 & 0.83 & 1363.2 & 1400.6 & 1527.7 & 1430.5 & 86.3 \\
\hline 26 & 0.61 & 920.4 & 1045.4 & 1045.3 & 1003.7 & 72.1 \\
\hline 27 & 0.61 & 926.5 & 1059.2 & 1049.2 & 1011.6 & 73.9 \\
\hline 28 & 0.61 & 896.8 & 1031.6 & 1007.8 & 978.7 & 72.0 \\
\hline 29 & 1.11 & 957.9 & 1029.3 & 1092.9 & 1026.7 & 67.5 \\
\hline 30 & 0.82 & 589.5 & 715.6 & 708.6 & 671.2 & 70.9 \\
\hline 31 & 0.82 & 561.4 & 675.8 & 661.9 & 633.1 & 62.5 \\
\hline 32 & 1.93 & 394.4 & 443.0 & 510.4 & 449.3 & 58.2 \\
\hline 33 & 1.44 & 176.5 & 258.1 & 257.5 & 230.7 & 46.9 \\
\hline 34 & 1.44 & 204.7 & 288.9 & 288.6 & 260.7 & 48.5 \\
\hline 35 & 2.87 & 191.6 & 225.6 & 208.6 & 208.6 & 17.0 \\
\hline 36 & 2.15 & 97.3 & 153.9 & 90.5 & 113.9 & 34.8 \\
\hline 37 & 2.15 & 99.5 & 149.3 & 86.0 & 111.6 & 33.4 \\
\hline
\end{tabular}


Table 6. Stiffness (lb/in) of VEwalls.

\begin{tabular}{|c|c|c|c|c|c|c|}
\hline Cycle & Displacement (in) & VEwall1 & VEwall2 & VEwall3 & Avergae & Standard. deviation \\
\hline 1 & 0.14 & 7137.6 & 8262.5 & 6376.9 & 7259.0 & 948.7 \\
\hline 2 & 0.14 & 7587.1 & 8729.9 & 7227.2 & 7848.1 & 784.6 \\
\hline 3 & 0.14 & 7692.2 & 8908.8 & 7048.4 & 7883.1 & 944.8 \\
\hline 4 & 0.14 & 7656.7 & 8908.8 & 7227.2 & 7930.9 & 873.7 \\
\hline 5 & 0.14 & 7728.1 & 8729.9 & 7366.5 & 7941.5 & 706.3 \\
\hline 6 & 0.14 & 7227.6 & 9071.6 & 7155.7 & 7818.3 & 1086.0 \\
\hline 7 & 0.21 & 7089.4 & 8346.0 & 6718.3 & 7384.6 & 853.1 \\
\hline 8 & 0.15 & 7378.5 & 8882.1 & 7308.6 & 7856.4 & 889.0 \\
\hline 9 & 0.15 & 7251.5 & 8491.5 & 6965.1 & 7569.4 & 811.3 \\
\hline 10 & 0.15 & 7442.0 & 8491.5 & 7060.6 & 7664.7 & 741.0 \\
\hline 11 & 0.15 & 7410.4 & 8650.8 & 7060.6 & 7707.3 & 835.6 \\
\hline 12 & 0.15 & 7378.5 & 8491.5 & 7092.5 & 7654.2 & 739.1 \\
\hline 13 & 0.15 & 7501.0 & 8523.8 & 7150.7 & 7725.2 & 713.4 \\
\hline 14 & 0.28 & 6791.9 & 8015.3 & 6443.3 & 7083.5 & 825.5 \\
\hline 15 & 0.2 & 7436.4 & 8518.6 & 6982.8 & 7645.9 & 789.0 \\
\hline 16 & 0.2 & 7083.3 & 8084.8 & 6773.1 & 7313.7 & 685.5 \\
\hline 17 & 0.2 & 6875.9 & 8251.8 & 6749.1 & 7292.3 & 833.4 \\
\hline 18 & 0.2 & 6892.3 & 8278.7 & 6773.1 & 7314.7 & 837.0 \\
\hline 19 & 0.2 & 7083.3 & 8251.8 & 6606.3 & 7313.8 & 846.7 \\
\hline 20 & 0.2 & 6910.8 & 8110.6 & 6790.6 & 7270.7 & 729.9 \\
\hline 21 & 0.55 & 5765.2 & 6055.3 & 5580.6 & 5800.4 & 239.3 \\
\hline 22 & 0.41 & 6249.2 & 5796.1 & 5956.8 & 6000.7 & 229.7 \\
\hline 23 & 0.41 & 5933.0 & 5548.2 & 5910.3 & 5797.2 & 215.9 \\
\hline 24 & 0.41 & 6153.8 & 5462.2 & 5986.9 & 5867.6 & 360.9 \\
\hline 25 & 0.83 & 4872.5 & 4819.6 & 5149.2 & 4947.1 & 177.0 \\
\hline 26 & 0.61 & 4205.5 & 5126.0 & 5168.2 & 4833.2 & 544.0 \\
\hline 27 & 0.61 & 3975.8 & 4947.9 & 4252.1 & 4391.9 & 500.9 \\
\hline 28 & 0.61 & 3856.7 & 4848.7 & 3817.1 & 4174.1 & 584.5 \\
\hline 29 & 1.11 & 3619.8 & 4209.9 & 3549.8 & 3793.2 & 362.6 \\
\hline 30 & 0.82 & 3762.7 & 4270.1 & 3691.1 & 3908.0 & 315.7 \\
\hline 31 & 0.82 & 3564.1 & 4001.2 & 3474.9 & 3680.1 & 281.7 \\
\hline 32 & 1.93 & FAILED & FAILED & FAILED & - & - \\
\hline 33 & 1.44 & - & - & - & - & - \\
\hline 34 & 1.44 & - & - & - & - & - \\
\hline 35 & 2.87 & - & - & - & - & - \\
\hline 36 & 2.15 & - & - & - & - & - \\
\hline 37 & 2.15 & - & - & - & - & - \\
\hline
\end{tabular}

The initial stiffness of OSBwall1 was $11,532.7 \mathrm{lb} /$ in and decreased significantly during primary cycles. This indicates that the transition to inelastic deformation occurs due to crushing of the wood around the sheathing fasteners, which only happens during primary cycles. Stiffness remained fairly constant within cycles of constant amplitude, implying that the majority of sheathing connections were not subjected to fatigue. The stiffness produced during cycles $1-6(0.14$ ”), cycles 8-13 (0.15") and cycles $15-20(0.20 ")$ was approximately $11,900 \mathrm{lb} / \mathrm{in}, 11,100 \mathrm{lb} / \mathrm{in}$ and 9,950 lb/in, respectively. The 
final stiffness of OSBwall1 at cycle 37 (2.15”) was 1,570.3 lb/in (a loss of 86.4\%). The greatest standard deviation was $21.6 \%$ of the average and occurred at cycle 23 ( 0.41 ").

For the GYPwalls the stiffness initially ranged from 4,460.4 lb/in to 4,752.6 lb/in and decreased almost immediately, indicating a small range of elasticity (less than 0.14 ") followed by inelastic deformation. The three shear wall specimens averaged an initial stiffness of 4,582.3 lb/in with a standard deviation of $152.0 \mathrm{lb} /$ in $(3.3 \%$ of the average), and decreased to an average final stiffness of $111.6 \mathrm{lb} /$ in with a standard deviation of $33.4 \mathrm{lb} /$ in $(29.9 \%$ of the average). Cycle 1 ( 0.14 ") produced an average stiffness of 4,582.3 lb/in, and declined almost linearly to 3,863.3 lb/in for cycle 6 . Stiffness during cycle $8\left(0.15^{\prime \prime}\right)$ was $3,082.6 \mathrm{lb} /$ in on average, compared to $3,035.3 \mathrm{lb} /$ in for cycle 13 . Cycle 15 (0.20") generated an average stiffness of 2,458.4 lb/in, and decreased to 2,359.6 lb/in. The standard deviation for the shear wall specimens was as low as $2.3 \%$ at cycle $22(0.41$ ”). GYPwall2 produced the lowest values of stiffness throughout most of the test, while GYPwall3 produced the highest values. The average loss in stiffness was 4,470.7 lb/in, or $97.6 \%$. As with the energy dissipation results, these values for stiffness are consistent but very low for an $8^{\prime} \times 8^{\prime}$ shear wall. By comparison, OSBwall1 produced an initial stiffness of 11,532.2 lb/in and a stiffness of 1,570.3 lb/in during cycle 52 (2.15").

The three VE gypsum shear wall specimens averaged an initial stiffness of 7,259.0 lb/in, which remained fairly constant throughout the first 20 cycles $(\leq 0.28$ "). Stiffness decreased approximately $500 \mathrm{lb} /$ in during primary cycles $(1,7$ and 14). The standard deviation for the first cycle stiffness was $948.7 \mathrm{lb} / \mathrm{in}$ (13.1\% of the average). At cycle 21 (0.55"), the average stiffness dropped to 5,800.4 lb/in. Then, at cycle $24(0.41$ "), stiffness began to drop almost linearly with respect to cycle number until cycle 32 (1.93"), during which all specimens failed. Therefore, by the end of the test, all VE gypsum shear walls sustained a total loss in stiffness. Had the gypsum wallboard panels remained intact and the stiffness continued to decline linearly, the final stiffness would have been approximately 2,000 lb/in.

The decrease in stiffness for the VE gypsum shear walls resembles the behavior of the VE gypsum connections, which exhibited a decrease in stiffness after 32 cycles of shear displacement. They too showed a linear decrease in stiffness after a period of constant stiffness. As with the VE gypsum connections, the VE gypsum shear walls did not exhibit signs of yielding or permanent damage prior to the sheathing failure. Therefore, it is likely that the decrease in stiffness was due to a change in the temperature, due to heat buildup, within the viscoelastic polymer. The loss of stiffness due to temperature change is well documented $[15,16,18]$.

\section{Wall Performance and Damage Results}

Damage to the OSBWalls was restricted to localized deformations near the sheathing connections and included nail withdrawal, nail pull-through and flaking of the OSB, as shown in Figures 13-15. In some areas, the nail withdrawal allowed the sheathing to pull away from the frame. Damage to the sheathing connections occurred along the center stud, top sill plate and double end stud (actuator side). Crushing of the wood sheathing and bending of the nails were observed similar to sheathing connections deformed in a manner similar to the nailed OSB connection specimens reported in a previous connection study [3]. 
Figure 13. Damage along the center stud and top sill plate.

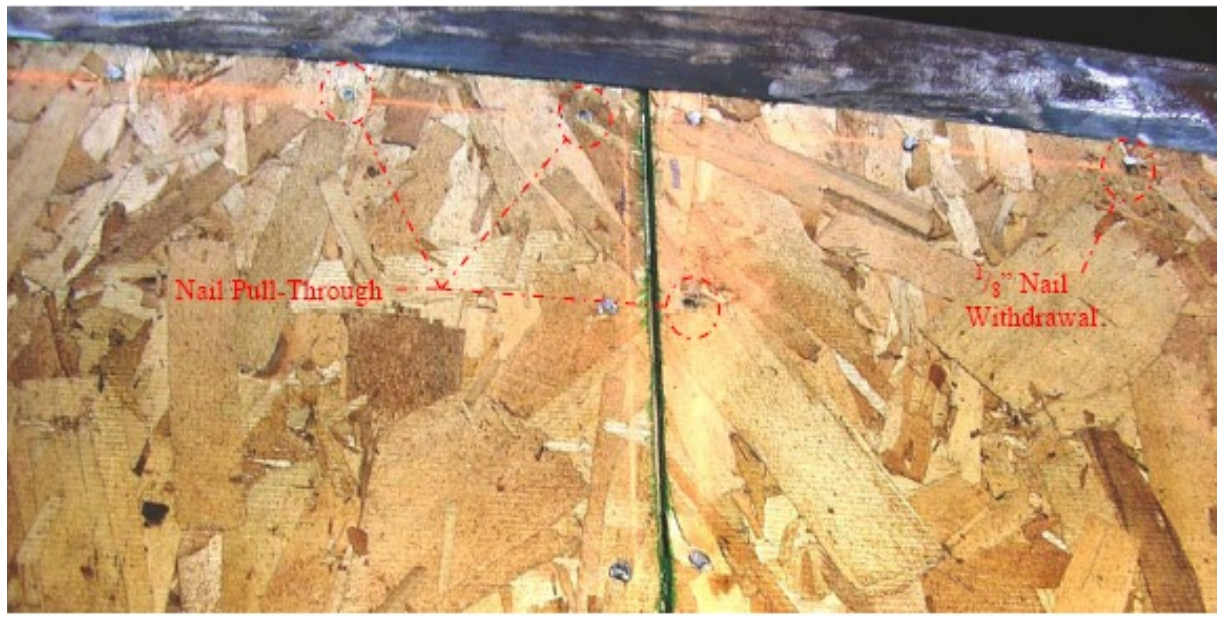

Figure 14. Nail pull-through along the center stud.

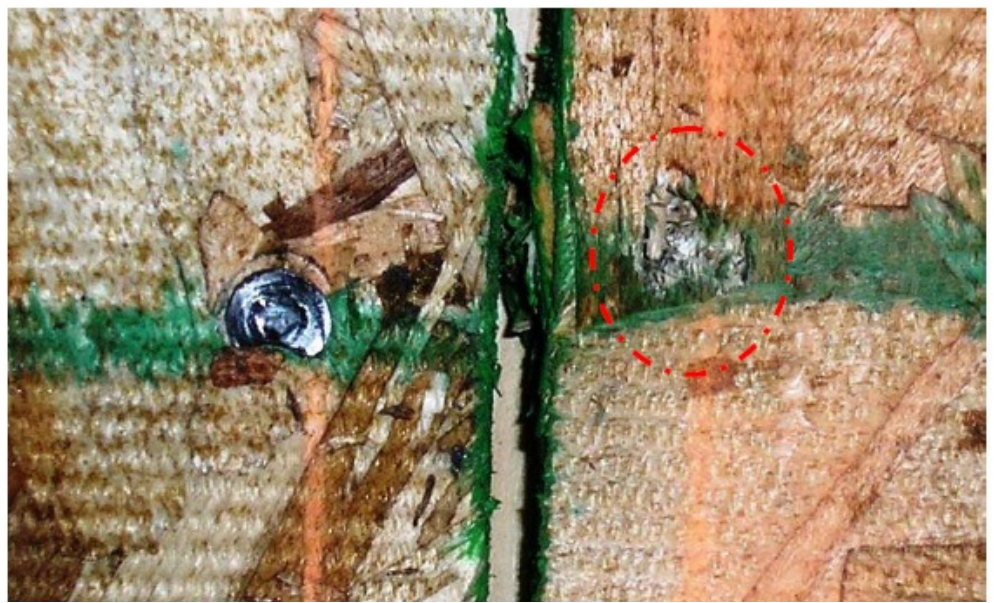

Figure 15. Nail pull-through along the center stud.
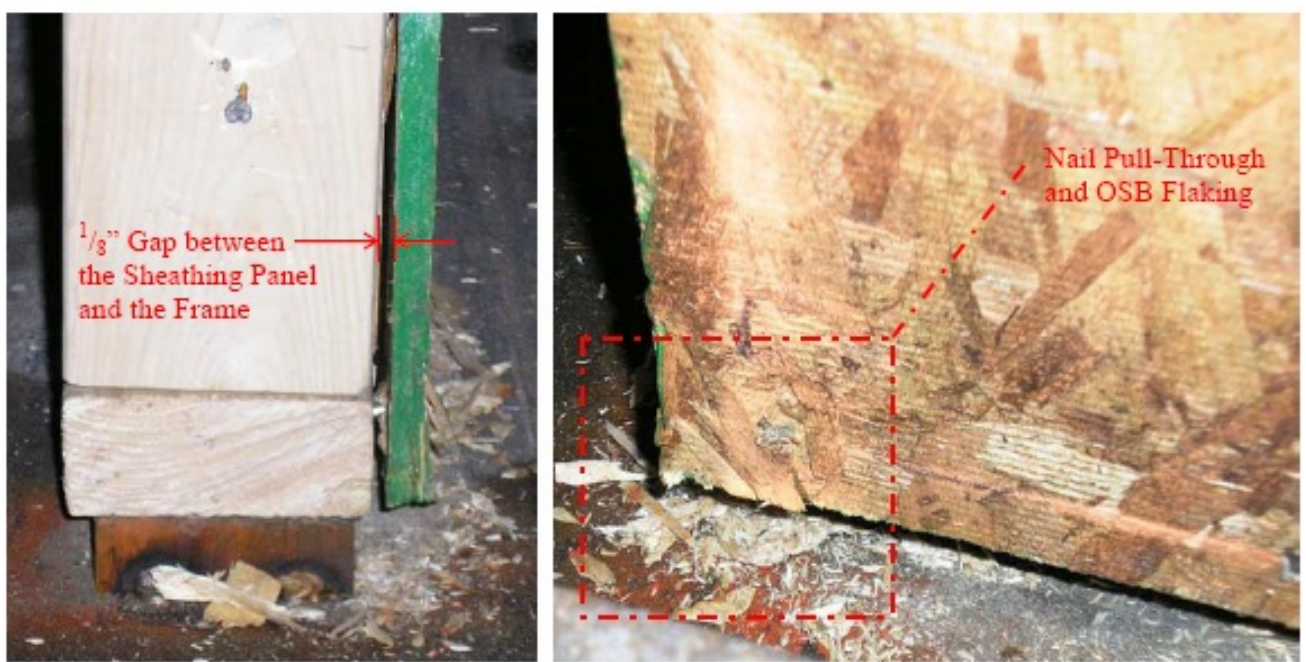

The wood frame remained intact throughout the test, as did the OSB sheathing panels. Sheathing connections along the field studs were also in good condition. However, the degradation of stiffness suggests significant inelastic behavior and permanent deformation. Had this wall been located in an 
actual structure during an earthquake, it would be in need of significant repair-specifically, re-nailing along the perimeter of each sheathing panel would be required.

Global damage sustained by the baseline GYPwalls included separation of the wallboard panels from the wood frame, as shown in Figure 16. The separation was more severe at the top of the walls (over 3/4"), whereas the bottom of the walls did not separate more than $1 / 4$ ". The separation was most likely due to localized damage sustained at the sheathing connections, which was worse at the top half of the wall (see Figure 16). The wood frames remained intact throughout all three tests.

Figure 16. Separation of Gypsum Wallboard from Wood Frame.

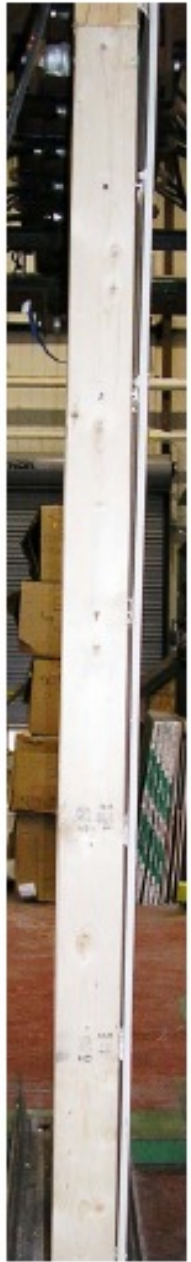

GYPwall1

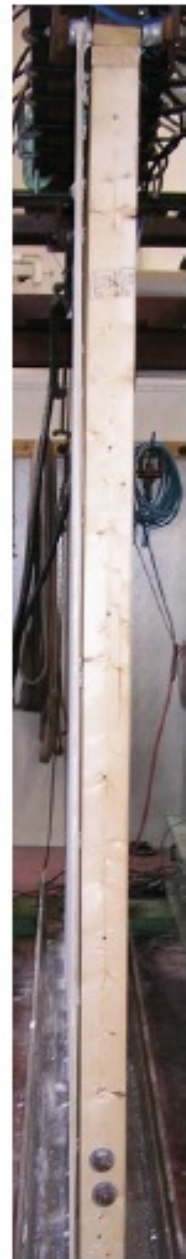

GYPwall2

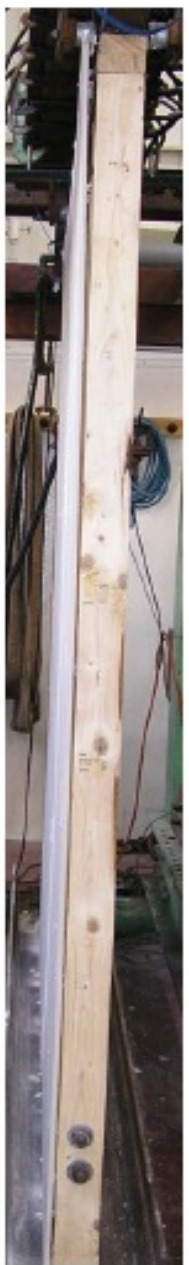

GYPwall3

The most severe localized damage was observed near the corners of the gypsum wallboard panels. Portions of the panels were crushed and torn by the dowel-type fasteners, as shown in Figure 17. This occurred near the corners and along the bottom sill plate, where the sheathing separation was minimal. Bulging of the wallboard was also observed near the fasteners. The heads of the drywall screws, which were slightly over-driven, slid just beneath the outer veneer of the wallboard when displaced, creating a bulging effect on the sheathing surface. This occurred along the field studs and top sill plate, where fastener pull-through was more evident as shown in Figure 18. Overall, the damage observed was substantial, which can be attributed to using rigid dowel-type fasteners with easily crushable gypsum 
sheathing panels. Had these walls been located in an actual structure during an earthquake, they would certainly be in need of repair - specifically, total replacement of the drywall panels.

Figure 17. Typical Damage to Gypsum Wallboard Corners.
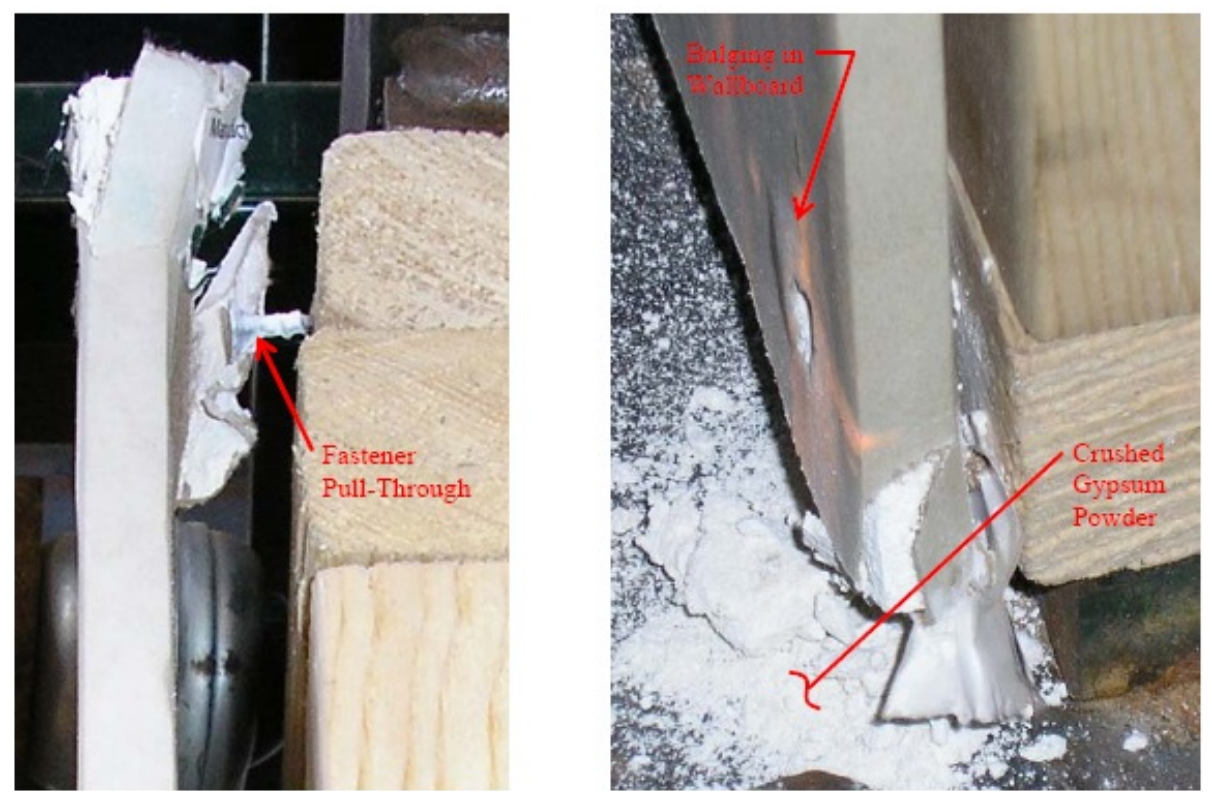

Figure 18. Typical Damage to Gypsum Sheathing Connections.

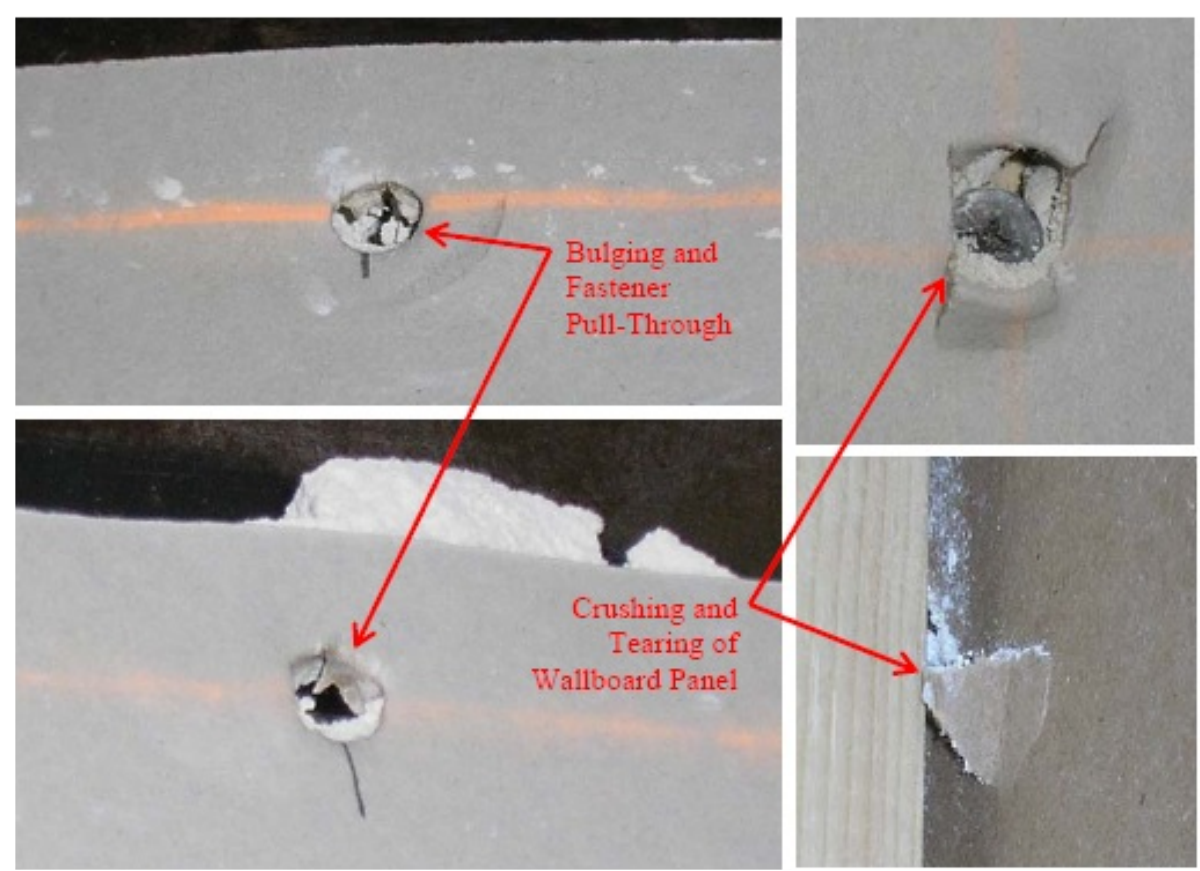

For all VEwalls during the first 31 cycles of displacement, there were no visible or audible signs of damage to the wood, gypsum, or VE polymer of all three specimens. All components of the VE gypsum connections remained completely adhered even when forces exceeded 6,000 lbs. The only indication of possible damage is the decrease in stiffness beginning at cycle 21 ( 0.55 ”). Though the decrease in stiffness is not expected to be a result of permanent damage, the possibility can not be ruled out. 
Immediately following cycle 31, all three walls failed due to excessive tensile stresses in the gypsum wallboard, leading to permanent damage of the sheathing panels, as shown in Figure 19. The damage consisted of long, diagonal cracks through the wallboard panels oriented perpendicular to the direction of the principal tensile stresses. Cracks were generally located on the lower and upper corners of the sheathing panels, and propagated along the center stud and sill plates. The failures were brittle, as there were no indications that a failure was imminent. Essentially, the integrity of the VEwalls relied on the capacity of the paper veneers on either side of the wallboard. Figures 19-23 illustrate the damage sustained by the three specimens. While the failures were unpredicted, it is essential to note that prior to a target displacement of 1.9 in, there was no visual or audible sign of damage.

Figure 19. Tension failure of gypsum wallboard.

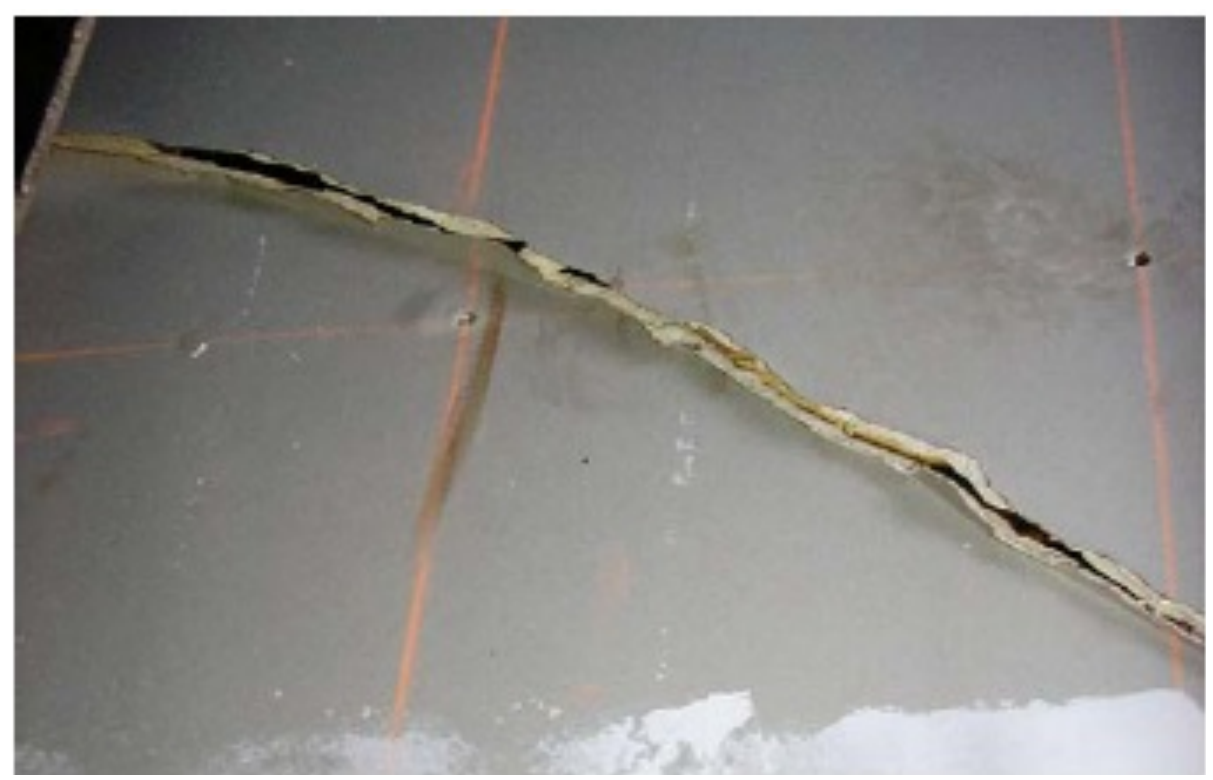

Figure 20. Damage to upper half of VEwall 1.

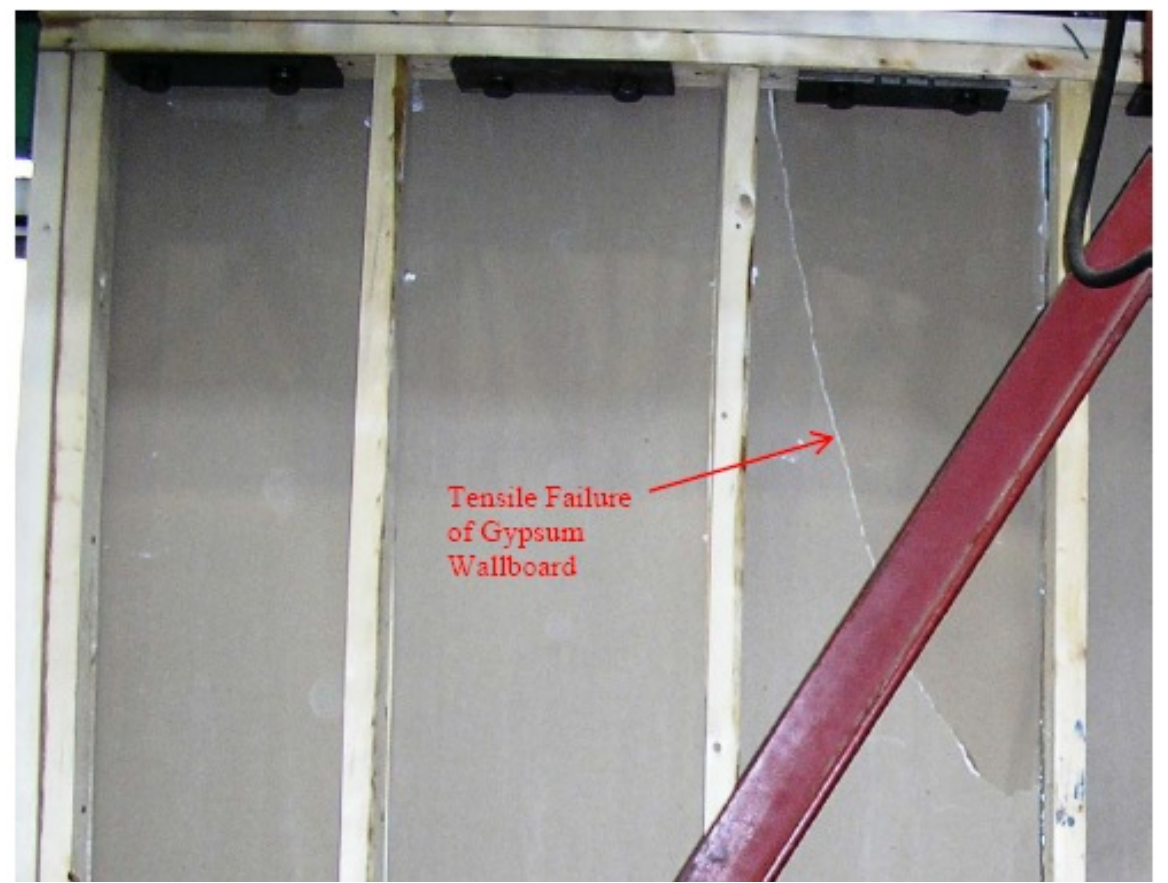


Figure 21. Damage to lower half of VEwall 1.

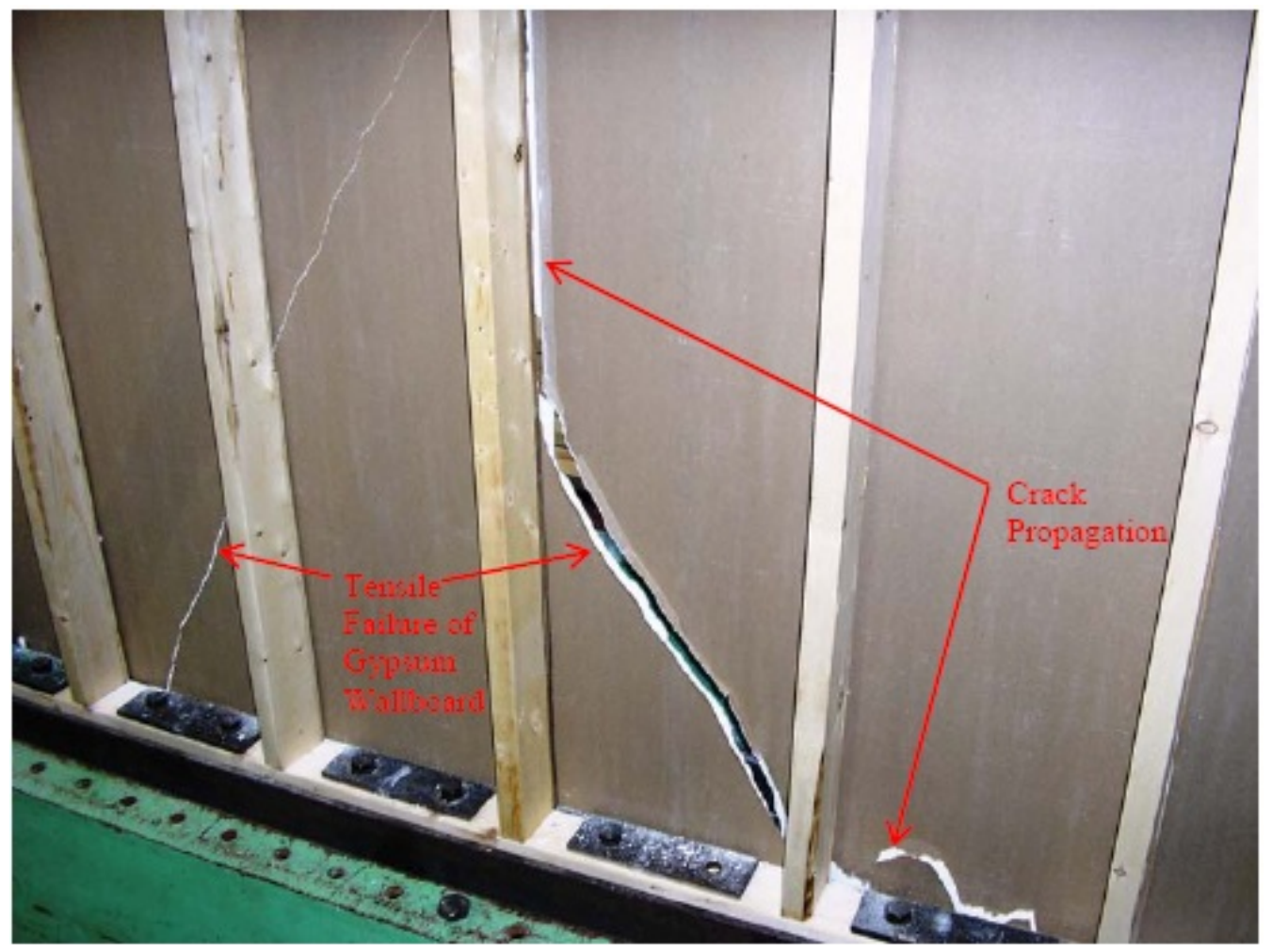

Figure 22. Crack propagation along the edge of VEwall 2.
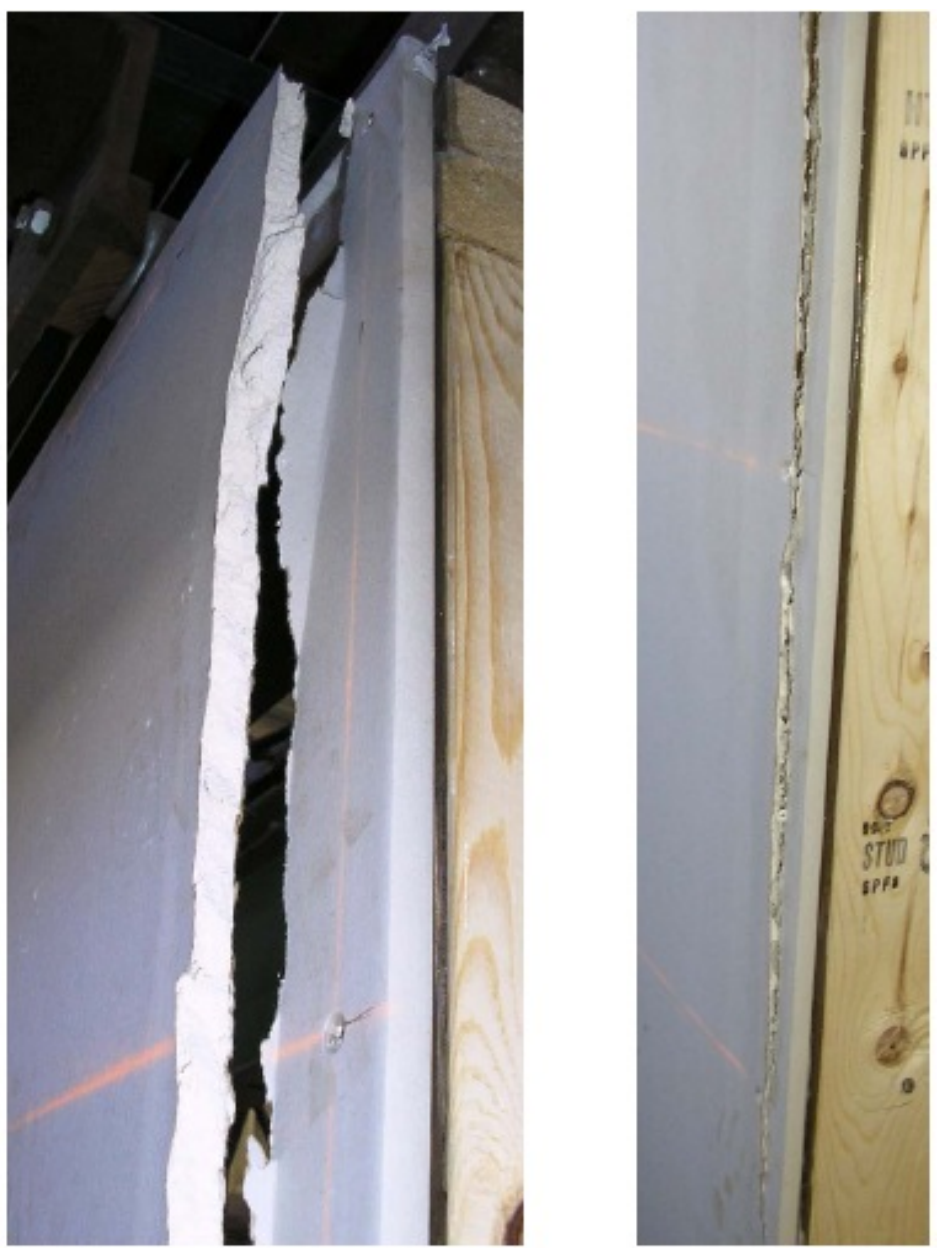
Figure 23. Damage to lower half of VEwall 3.



\section{Summary}

Three conventional gypsum shear walls and three viscoelastic shear walls were tested. The baseline walls used conventional screwed sheathing connections, whereas the VE shear walls utilized VE material along the perimeter of the sheathing panels. The walls were loaded at frequency of $1.0 \mathrm{~Hz}$ using a displacement-based load protocol recommended by CUREE. Table 7 provides a summary of the performance.

Table 7. Summary of wall performance.

\begin{tabular}{|c|c|c|c|c|c|}
\hline $\begin{array}{c}\text { Type of } \\
\text { shear wall }\end{array}$ & $\begin{array}{c}\text { ED at cycle } \\
29 \text { (lb-in) }\end{array}$ & $\begin{array}{c}\text { Total ED to } \\
\text { cycle } 31 \text { (lb-in) }\end{array}$ & $\begin{array}{c}\text { Initial K } \\
\text { (lb/in) }\end{array}$ & $\begin{array}{c}\mathrm{K} \text { at } \\
\text { cycle } 31\end{array}$ & Damage summary \\
\hline OSBwall & $4,673.6$ & $30,177.0$ & $11,558.3$ & $4,019.4$ & $\begin{array}{l}\text { Nail withdrawal } \\
\text { Nail pull-through } \\
\text { OSB flaking } \\
\end{array}$ \\
\hline GYPwall & $1,157.8$ & $5,730.0$ & $4,582.3$ & 633.1 & $\begin{array}{l}\text { Sheathing separation from frame } \\
\text { Fastener pull-through } \\
\text { Bulging of gypsum near fasteners }\end{array}$ \\
\hline VEwall & $6,355.3$ & $34,931.6$ & $7,259.0$ & $3,680.1$ & $\begin{array}{c}\text { No damage }<1.1 \text { inches of displacement } \\
\text { Long, diagonal cracks due to sheathing } \\
\text { Tension failure } \\
\text { Sheathing separation from frame }\end{array}$ \\
\hline
\end{tabular}




\section{Conclusions}

Based on the results of the experimental program described, the following conclusions with respect to energy dissipation, stiffness, and wall damage can be made:

\subsection{Energy Dissipation}

1. The OSB sheathed walls and gypsum sheathed walls dissipate energy via inelastic deformation of the sheathing connections, whereas the VE walls dissipate energy via viscous damping of the VE polymer;

2. At a wall displacement of 1.11 inches (cycle 29), the energy dissipation of the VE gypsum walls is $36 \%$ greater than OSB walls and over $400 \%$ greater than the non-structural conventional walls with the same sheathing;

3. The VE gypsum walls dissipated more energy than the OSB walls through 31 cycles of displacement and over 5 times as much energy than the conventional gypsum walls;

4. The average total energy dissipated by the VE gypsum shear walls through 31 cycles of displacement was greater than that dissipated by the OSB walls;

5. The average total energy dissipated by the VE walls was 5 times greater than that dissipated by the non-structural gypsum walls;

6. Viscoelastic gypsum shear walls dissipate energy with greater consistency. The standard deviations (percentage) for total energy dissipated by each type of shear wall are as follow: $3.9 \%$ for VE gypsum, $7.1 \%$ for OSB, $8.5 \%$ for gypsum.

\subsection{Stiffness}

1. Viscoelastic gypsum shear walls produce an initial stiffness of $7,259 \mathrm{lb} / \mathrm{in}, 37 \%$ less than the OSB shear walls and 58\% greater than the gypsum shear walls;

2. Gypsum and OSB shear walls lose stiffness immediately when displaced, whereas VE gypsum shear walls do not lose stiffness until cycle 21 (0.55"). The gypsum and OSB shear walls average a $50 \%$ loss of stiffness by cycles $21(0.55$ ”) and $25(0.83$ ”), respectively. On average, the VE gypsum shear walls do not lose $50 \%$ stiffness prior to failure;

3. Cycle 31 (0.82") is the last cycle for which all VE gypsum shear wall specimens remained intact. During this cycle, the VE gypsum shear walls average 3,680 lb/in, an increase of $481 \%$ over the conventional gypsum shear walls. By comparison, the OSB shear walls averaged a stiffness of 3,788 lb/in during cycle 31 . All three VE gypsum shear walls failed during cycle 32 (1.93"), resulting in a total loss of stiffness.

\subsection{Wall Damage}

1. Damage to the OSB and gypsum shear walls consists of localized deformation near the sheathing connections and the corners of the sheathing panels. Separation between the sheathing and the frame is also present (3/4" for the gypsum shear walls and $1 / 8$ " for the OSB shear wall). These findings are similar to that seem in other studies; 
2. The VE gypsum shear walls do not display any visual signs of damage to the sheathing or the sheathing connections prior to cycle 32 (1.93”). During cycle 32, all three specimens sustain a brittle failure due to excessive tensile stresses in the gypsum wallboard panels, resulting in long, diagonal cracks propagating through the panels and a loss of capacity;

3. Viscoelastic material offers gypsum shear walls the potential to be used as substantial structural members, while reducing the risk of costly damage during seismic events.

\section{Acknowledgments}

The National Science Foundation (NSF) and Partnership for Advancing Technology in Housing (PATH) is acknowledged for partial funding of this work (Grant No. CMS-0229724). The academic and technical mentoring of Harry "Tripp" Shenton is greatly appreciated by the authors.

\section{References}

1. Seible, F.; Filiatrault, A.; Uang, C.M.; Eds. Proceedings of the Invitational Workshop on Seismic Testing, Analysis and Design of Woodframe Construction; California Universities for Research in Earthquake Engineering: Berkeley, CA, USA, 1999.

2. American Wood Council. Manual for Engineered Wood Construction; American Forrest and Paper Association: Washington, DC, USA, 2001.

3. Foley, D. An Experimental Investigation of Viscoelastic Material in Wood Connections and Shearwalls. Master's Thesis, Villanova University, Villanova, PA, USA, 2005.

4. Filiatrault, A.; Fischer, D.; Folz, B.; Uang, C. Seismic testing of two-story woodframe house: Influence of wall finish materials. ASCE J. Struct. Eng. 2002, 128, 1337-1345.

5. McMullin, K.M.; Merrick, D.S. Seismic damage thresholds for gypsum wallboard partition walls. J. Archit. Eng. 2007, 13, 22-29.

6. Wolfe, R.W. Contribution of Gypsum Wallboard to Racking Resistance of Light-Frame Walls; United States Department of Agriculture: Washington, DC, USA, 1983.

7. Patton-Mallory, M.; Gutkowski, R.M.; Soltis, L.A. Racking Performance of Light-Frame Walls Sheathed on Two Sides; Forest Products Laboratory: Madison, WI, USA, 1984.

8. Arnold, A.E.; Uang, C.; Filiatrault, A. Cyclic Behavior and Repair of Stucco and Gypsum Woodframe Walls: Phase I; Consortium of Universities for Research in Earthquake Engineering: Richmond, CA, USA, 2003.

9. Filiatrault, A.; Christovasili, I.P.; Wanitkorkul, A.; van de Lindt, J.W. Experimental seismic response of a full-scale light-frame wood building. ASCE J. Struct. Eng. 2010, 136, 1262-1272.

10. Van de Lindt, J.W.; Pei, S.; Pryor, S.E. Construction and experimental seismic performance of a full-scale six-story light-frame wood building. In Proceedings of the 12th East Asia-Pacific Conference on Structural Engineering and Construction, Hong Kong, China, 26-28 January 2011.

11. Van de Lindt, J.W.; Gupta, R.; Pei, S.; Tachibana, K.; Araki, Y.; Rammer, D.; Isoda, H. Damage assessment of a full-scale six-story wood-frame building following triaxial shake table tests. ASCE J. Perform. Construct. Facil. 2012, 25, 17-25. 
12. Shinde, J.K.; Symans, M.D.; Hongyan, L.; van de Lindt, J.W. Seismic performance assessment of woodframed structures with energy dissipation systems. In Proceedings of the 18th Analysis and computation Specialty Conference-Structures Congress, Vancouver, BC, Canada, 24-26 April 2008.

13. Van de Lindt, J.W.; Hongyan, L.; Symans, M.D.; Shinde, J.K. Seismic performance and modeling of a half-scale base-isolated wood frame building. J. Earthq. Eng. 2011, 15, 469-490.

14. Blasetti, A.S.; Hoffman, R.M.; Dinehart, D.W. Simplified hysteretic finite element model for wood and viscoelastic polymer connections for the dynamic analysis of shear walls. ASCE J. Struct. Eng. 2008, 134, 77-86.

15. Joye, D.D.; Dinehart, D.W. Improved viscoelastic damping for earthquake resistant wood structures. Int. J. Polym. Mater. 2007, 56, 55-64.

16. Dinehart, D.W.; Leese, K.A.; Patterson, S. Cyclic performance of a viscoelastic connection for use in wood-frame and steel-frame gypsum shearwalls. In Proceedings of the 11th World Conference on Timber Engineering, Riva del Garda, Italy, 20-24 June 2010.

17. Dinehart, D.W.; Joye, D.D.; de Mendoza, G.E. Viscoelastic polymers improve the cyclic performance of wood connections. In Proceedings of the 8th World Conference on Timber Engineering, Lahti, Finland, 14-17 June 2004.

18. Dinehart, D.W.; Lewicki, D.E. Viscoelastic material as a seismic protection system for wood-framed buildings. In Proceedings of the 2001 Structures Congress \& Exposition, Washington, DC, USA, 21-23 May 2001.

19. Krawinkler, H.; Parisi, F.; Ibarra, L.; Ayoub, A.; Medina, R. Development of a Testing Protocol for Woodframe Structures; Consortium of Universities for Research in Earthquake Engineering: Richmond, CA, USA, 2001.

20. Dinehart, D.W.; Shenton, H.W., III. Comparison of the static and dynamic response of timber shear walls. ASCE J. Struct. Eng. 1999, 125, 686-695.

21. Shenton, H.W., III; Dinehart, D.W.; Elliott, T.E. Stiffness and energy degradation of wood frame shear walls. Can. J. Civ. Eng. 1998, 25, 412-423.

22. Dinehart, D.W.; Blasetti, A.S.; Shenton, H.W., III. The experimental cyclic performance of viscoelastic gypsum connections and shear walls. J. Struct. Eng. 2008, 134, 87-95.

(C) 2012 by the authors; licensee MDPI, Basel, Switzerland. This article is an open access article distributed under the terms and conditions of the Creative Commons Attribution license (http://creativecommons.org/licenses/by/3.0/). 